NBER WORKING PAPER SERIES

\title{
THE EQUILIBRIUM APPROACH TO \\ EXCHANGE RATES: THEORY \\ AND TESTS
}

\author{
Prakash Apte \\ Piet Sercu \\ Raman Uppal
}

\author{
Working Paper 5748 \\ NATIONAL BUREAU OF ECONOMIC RESEARCH \\ 1050 Massachusetts Avenue \\ Cambridge, MA 02138 \\ September 1996
}

The authors are grateful for suggestions and comments to Richard Baillie, Anton Barten, Geert Bekaert, Martin Boileau, Paul De Grauwe, Mick Devereux, Harris Dellas, Geert Gielen, Ronald MacDonald, Gonzalo Rubio, Frans Spinnewyn, René Stulz, and workshop participants at Universidad del Pais Vasco, K.U. Leuven, Center for European Policy Research, and the 1995 meetings of the European Finance Association. The usual disclaimer applies. This paper was presented at the NBER conference "Universities Research Conference on the Determination of Exchange Rates" and is part of NBER's project on International Capital Flows. We are grateful to the Center for International Political Economy for the support of this project. Any opinions expressed are those of the authors and not those of the National Bureau of Economic Research.

(C) 1996 by Prakash Apte, Piet Sercu and Raman Uppal. All rights reserved. Short sections of text, not to exceed two paragraphs, may be quoted without explicit permission provided that full credit, including $\mathbb{C}$ notice, is given to the source. 


\title{
THE EQUILIBRIUM APPROACH TO EXCHANGE RATES: THEORY AND TESTS
}

\begin{abstract}
We characterize the equilibrium exchange rate in a general equilibrium economy without imposing strong restrictions on the output processes, preferences, or commodity market imperfections. The nominal exchange rate is determined by differences in initial wealths-the currencies of richer countries tend to be overvalued by PPP standards-and by differences of marginal indirect utilities of total nominal spending. Changes in the exchange rate mirror differences in growth rates of real spending weighted by relative risk-aversion (which can be time-varying and can differ across countries), and in the case of non-homothetic utility functions, differences in inflation rates computed from marginal spending weights. Thus, standard regression or cointegration tests of PPP suffer from missing-variables biases and ignore variations in risk aversions across countries and over time. We also present cointegration tests of the version of the model with constant relative risk aversion (CRRA) and homothetic preferences. When nominal spending is given an independent role (next to prices) in the short-term dynamics, both PPP and the CRRA model become acceptable.
\end{abstract}

Prakash Apte

I.I.M. Bangalore

Bannerghatta Road

Bangalore 560076

INDIA

apte@iimb.ernet.in

Raman Uppal

Faculty of Commerce

University of British Columbia

2053 Main Mall

Vancouver, BC V6T 1Z2

CANADA

uppal@finance.commerce.ubc.ca
Piet Sercu

D.T.E.W.

K.U. Leuven

Naamsestraat 69

3000 Leuven

BELGIUM

piet.sercu@econ.kuleuven.ac.be 


\section{The Equilibrium Approach to Exchange Rates: Theory and Tests}

Relative to the monetary models of the exchange rate, "equilibrium" models offer the advantage of being based on mainstream micro-economics and general-equilibrium analysis. ${ }^{1}$ Still, these equilibrium models of the exchange rate often depend on very specific assumptions about the number of goods and countries, the utility functions and production processes, and the type of friction in the international goods markets. Our objective is to characterize the exchange rate in a general equilibrium setting without imposing strong restrictions on the model. In contrast to most of the Purchasing Power Parity (PPP) literature, where the relation between exchange rates and prices is derived rather informally, we show under what alternative sets of assumptions the general equilibrium model reduces to PPP, and, especially, how exchange rates are determined when PPP does not hold. We also formulate and implement a new test of PPP against a specific alternative.

On the theoretical front, we characterize the equilibrium exchange rate in a multi-country and multi-commodity economy where there may be fixed and/or proportional costs for reallocating goods across countries, and where agents' utility functions need not be homothetic, or of the HARA class, or identical across countries. Our main findings are the following:

(a) In general, the nominal exchange rate mirrors differences in initial wealths and marginal indirect utilities of nominal spending. The effect of initial wealths is that, by PPP standards, the currencies of richer countries tend to be overvalued. Necessary conditions for differences in marginal indirect utilities, on the other hand, are (a) commodity market imperfections and/or differences in consumption preferences, and (b), perhaps less predictably, risk-

\footnotetext{
${ }^{1}$ See, for example, Stockman (1980), Lucas (1982), Domowitz and Hakkio (1985), Svensson (1985a,b), Hodrick and Srivastava (1986), Stulz (1987), Stockman and Dellas (1989), Dumas (1992), Engel (1992a,b), Backus and Smith (1993), Bekaert (1994), and Sercu, Van Hulle, and Uppal (1995).
} 
aversion.

(b) The popular case of risk-neutrality and homothetic preferences has rather exceptional implications. First, under these assumptions relative PPP holds irrespective of commodity market imperfections and differences in consumption preferences. Second, initial wealth does not affect the equilibrium if (and only if) the assumptions of perfect goods markets and identical preferences are added.

(c) In another special case-with homothetic, constant relative risk aversion (CRRA) utility functions-we obtain a tractable and testable generalization of the traditional PPP equation. Specifically, according to the CRRA model there are two missing variables in the PPP equation (the two countries' nominal spendings); moreover, the elasticities of the exchange rate with respect to the price indices need not be identical across countries, and their sign differs from what PPP predicts.

(d) In a (more realistic) model with non-homothetic preferences, the nominal exchange rate change depends not only on the standard ("average") inflation differential across countries (as in the PPP model) but also on the inflation differential computed on the basis of marginal consumption weights, growth in real spending, and the (generally time-varying) degree of risk aversion in the two countries.

(e) From items (b) and (d), we infer that standard regression or cointegration tests of PPP suffer from missing-variables biases and ignore variations in risk aversions across countries and over time. In hyperinflation samples, relative PPP may seem to hold fairly well because the missing variables then behave quite similarly and because the elasticities of the exchange rate with respect to all variables sum to unity.

We complement our theoretical analysis of the exchange rate with empirical test of a version of the model with constant relative risk aversion and homothetic preferences, using the Johansen and Juselius (1990) cointegration framework. We find, first, that the outcome of the tests 
crucially depends on whether (and how) nominal spending is allowed to enter into the short-term dynamics of the exchange rate: If nominal spending is entirely absent from the short-term dynamics, or when only real spending is included in the vector autoregessions (VARs), we reject both PPP and the CRRA model. Second, when nominal spending is given an independent role (next to prices) in the short-term dynamics, both PPP and the CRRA model become acceptable. We provide a theoretical explanation for the inability to distinguish between the PPP and CRRA models in samples where nominal spending and price data have similar time paths.

The rest of this paper is organized as follows. In Section I, we present a generalized version of the Stockman (1980) equilibrium model. In Section II, we analyze deviations from Absolute PPP under homothetic utility-first for the general case, and then for the special cases of risk neutrality and constant relative risk aversion. We also discuss the implications of the CRRA model for cointegration tests of exchange rate models. In Section III, we test this special version of the model. As mentioned before, the results are ambiguous. In Section IV, we therefore return to theory. We derive a general model for changes in the exchange rate and we use this model to reinterpret regression tests of relative PPP and cointegration tests of the CRRA model. Section V concludes. A glossary summarizing the mathematical notation used in the paper is included at the end of Section V.

\section{The Economy and the Equilibrium Exchange Rate}

In this section, we first describe a model of a multi-country, multi-good economy with imperfect commodity markets. We impose only a few (very standard) restrictions on preferences, and none on production or endowment processes or on the degree or type of commodity market imperfections. In the second part of this section, we characterize the exchange rate in this general setting. 
The economy that we consider consists of $M \geq 2$ countries. We focus on two arbitrarily selected countries that are referred to as the home country (subscript $k=1$ ) and the foreign country $(\mathrm{k}=2)$. Each country has a representative consumer with a standard, strictly quasi-concave utility function defined over $\mathrm{N} \geq 1$ goods. Across countries these representative individuals may differ in terms of risk-aversion, consumption preferences, and initial wealths.

The outputs of each of the $\mathbf{N}$ goods can be stochastic over time. The economies could be exchange economies where output is given by exogenous endowment processes (as in Stockman (1980) and Lucas (1982)) or production economies with endogenous investment decisions (as in Dumas (1992) and Stulz (1987)). The specification of the production or endowment processes is quite general: some goods may be produced everywhere, while other goods may be produced only in some countries. International shipment of these goods may be costly for some or even all of these goods ; these costs are assumed to be purely variable costs (as in Dumas (1992) and Sercu $e t$ al. (1995)). Given these costs for transferring goods across countries, some goods may be traded all the time, some may be tradable in the strict sense (that is, traded only if the price difference is sufficiently large to justify incurring the shipment costs), and some goods may be de facto nontradable. ${ }^{2}$ For simplicity, money is introduced into the model via the Lucas (1982) cash-in-advance constraint. $^{3}$

We assume that financial markets are complete and perfect. Thus, the outcome of decentralized consumption and investment decisions is identical to the solution of a central

\footnotetext{
${ }^{2}$ Other frictions could be introduced, like shipment lags (goods sent from one country at time $t$ arrive only at time $t+1$ ) and transaction lags (a trade arranged at time $t$ is implemented at time $t+1$ only). It can be shown that neither transaction lags nor shipment lags affect any of our conclusions.

${ }^{3}$ Essentially the same results would be obtained if real money balances were introduced as an argument in the utility function, except that the price index will contain the interest cost of money balances-see, for instance, Stulz (1987).
} 
planner's problem of the form

$$
\operatorname{Max} E_{t}\left[\int_{t}^{T} U_{1}\left(\underline{c}_{1}(s)\right) d s\right]+\sum_{k=2}^{M} \theta_{k} E_{t}\left[{ }_{t}^{T} U_{k}\left(\underline{c}_{k}(s)\right) d s\right]
$$

This optimization is constrained by an opportunity set that depends on the currently available outputs, the production functions, and the shipping technology. We do not need to specify the opportunity set explicitly. In (1.1), $\underline{c}_{k}(t)$ is the vector of consumption quantities $c_{k j}(t)$ of $\operatorname{good} j(=1$, $\ldots, N)$ consumed by the representative individual in country $k(=1, \ldots, M)$ and $U_{k}$ is the utility function of the representative investor in country $k$. The relative weight assigned by the central planner to each of the other countries, $\theta_{k}$, generally is a function the initial distribution of wealth in the equivalent decentralized problem. ${ }^{4}$ In turn, these initial wealths depend on the initial endowments, the characteristics of the (stochastic) investment functions or endowment processes, the frictions in the international markets for consumption and capital goods, and the utility functions. ${ }^{5}$ For example, one sufficient (but not necessary) set of assumptions to obtain $\theta_{k}=1$ is when the utility functions, the initial endowments, and the parameters of the output process of all countries are identical.

Given the above assumptions, we now derive the exchange rate. Define the net endowment of each good in each country as the amount available for consumption. In an exchange economy, the net endowments are, of course, identical to the gross endowments, while in a production economy we need to set aside the resources needed for the optimal investments identified from the

\footnotetext{
${ }^{4}$ In a decentralized economy with a complete capital market, there exists a portfolio strategy that allows investors to implement the central planner's solution. For example, consider the case where $\theta_{k}=1$, utility functions are equal, and shipment costs are zero. The central planner's solution then is to give each of the $M$ countries an equal amount of consumption. The portfolio strategy that implements this plan is that each country holds $1 / \mathrm{M}$-th of the shares of each productive asset, so that each country can obtain $1 / \mathrm{M}$-th of world output.

${ }^{5}$ When commodity preferences are not equal, $\theta_{2}$ obviously depends also on the (arbitrarily chosen) size of the reference bundle in which each country's real wealth is expressed.
} 
solution of (1.1). If (1.1) is maximized, it must be impossible to further increase the utility from current consumption in one country without reducing either consumption in another country or investments. Denote the aggregate utility of the central planner from immediate consumption by (boldface) U(.):

$$
\mathrm{U}(\mathfrak{c}(\mathrm{t})) \equiv \mathrm{U}_{1}\left(\underline{c}_{1}(\mathrm{t})\right)+\sum_{\mathrm{k}=2}^{\mathrm{M}} \theta_{\mathrm{k}} \mathrm{U}_{\mathrm{k}}\left(\underline{c}_{\mathrm{k}}(\mathrm{t})\right)
$$

Thus, in the optimum identified from (1.1), $\mathbf{U}(\underline{c}(t))$ must be at its maximum subject to the feasible set implied by the net endowments and the transaction technology. From this Pareto-optimality of consumption, it follows that the relative price for any pair of goods can be read off as the marginal rate of substitution (MRS), along $\mathbf{U}(\underline{c}(t))$, in the optimum.

Let us chose, as the pair of goods, one unit of good $\mathrm{j}$ located in country 1 and one unit of the same good $j$ located in country 2 . The local-currency prices of these goods are denoted by $p_{1 j}(t)$ and $\mathrm{p}_{2 \mathrm{j}}(\mathrm{t})$. Because the relative price has to be computed from nominal prices expressed in a common numeraire, we need a reference numeraire and an exchange rate. Without loss of generality, we select currency 1 as the numeraire, and use the symbol $S(t)$ to denote the exchange rate (units of country-1 currency per unit of currency 2). Below, we write the condition that equates the relative price to the MRS:

$$
\frac{S(t) p_{2 j}(t)}{p_{1 j}(t)}=\frac{\partial U(t) / \partial c_{2 j}(t)}{\partial U(t) / \partial c_{1 j}(t)}
$$

In Proposition 1, below, we now link the nominal exchange rate to the marginal indirect utility function. ${ }^{6}$ The indirect utility function, $V\left(M_{k}(t), p_{k}(t)\right)$, is defined as

$$
\mathrm{V}\left(\mathrm{M}_{\mathrm{k}}(\mathrm{t}), \underline{\mathrm{p}}_{\mathrm{k}}(\mathrm{t})\right) \equiv \underset{\mathrm{c}_{\mathrm{kj}}(\mathrm{t})}{\operatorname{Max}}\left\{\mathrm{U}_{\mathrm{k}}\left(\underline{c}_{k}(\mathrm{t})\right)-\Lambda_{\mathrm{k}}(\mathrm{t})\left[\sum_{\mathrm{j}=1}^{\mathrm{N}} \mathrm{c}_{\mathrm{kj}}(\mathrm{t}) \mathrm{p}_{\mathrm{kj}}(\mathrm{t})-\mathrm{M}_{\mathrm{k}}(\mathrm{t})\right]\right\}
$$

where $M_{k}(t)$ is the amount of nominal spending, expressed in units of currency $k$. The marginal

\footnotetext{
${ }^{6}$ Proposition 1 is a familiar result in the Unbiased Expectations literature; see, for instance, Lewis (1995).
} 
indirect utility of nominal spending in country $\mathrm{k}$ is the multiplier, $\Lambda(\mathrm{t})$, in the above optimization problem:

$$
\Lambda_{k}(t)=\frac{\partial V\left(M_{k}(t), \underline{p}_{k}(t)\right)}{\partial M_{k}(t)}
$$

Proposition 1: The nominal exchange rate, $S(t)$, is proportional to the ratio of the marginal indirect utility of total nominal spending in the two countries:

$$
S(t)=\theta_{2} \frac{\Lambda_{2}(t)}{\Lambda_{1}(t)}
$$

Proof: Substitute (1.2) into (1.3) to relate the central planner's MRS to the marginal utilities of the two countries:

$$
\frac{S(t) p_{2 j}(t)}{p_{1 j}(t)}=\frac{\theta_{2} \partial U_{2}(t) / \partial c_{2 j}(t)}{\partial U_{1}(t) / \partial c_{1 j}(t)}
$$

Then solve for the exchange rate:

$$
S(t)=\theta_{2} \frac{\frac{\partial U_{2}\left(\underline{c}_{2}(t)\right) / \partial c_{2 j}(t)}{p_{2 j}(t)}}{\frac{\partial U_{1}\left(\underline{c}_{1}(t)\right) / \partial c_{1 j}(t)}{p_{1 j}(t)}} .
$$

To obtain (1.5), we substitute $\partial \mathrm{U}_{\mathrm{k}}(\mathrm{t}) / \partial \mathrm{c}_{\mathrm{kj}}(\mathrm{t})=\Lambda_{\mathrm{k}}(\mathrm{t}) \mathrm{p}_{\mathrm{jk}}(\mathrm{t})$, which is the first-order condition obtained from the optimization problem defined in (1.4).

We wish to study the implications of Proposition 1 for the real exchange rate and deviations from PPP. In Section II, the focus is on the level of the exchange rate. Most of this discussion is confined to the special case of homothetic utility functions. In this section we obtain a new sufficient condition for PPP, and a testable generalized equation that contains PPP as a special case. We test this model in Section III. In the non-homothetic preferences case, it is rarely possible to obtain a tractable characterization of the level of the exchange rate from (1.5); however, as shown in Section IV, an interesting general characterization of changes in exchange rates is always possible. 


\section{Characterizing the Level of the Exchange Rate}

In this section, we consider the special case of homothetic preferences. We first discuss the general implications of homothetic preferences for the exchange rate equation (1.5). We then consider two alternative special cases that both imply PPP, and we derive the CRRA exchange rate model of which PPP is a special case. Lastly, we discuss the implications of our theoretical results for empirical tests of PPP.

\section{II.A Implications of the Assumption of Homothetic Utility Functions}

By definition, a homothetic utility function can be written as $U_{k}\left(\underline{c}_{k}(t)\right)=\Phi\left[u_{k}\left(\underline{c}_{k}(t)\right)\right]$, where $\mathrm{u}_{\mathrm{k}}\left(\underline{c}_{\mathrm{k}}(\mathrm{t})\right)$ is linear homogenous in the consumption quantities and where $\Phi_{k}$ is a positive transformation. The function $\mathrm{u}_{k}\left(\underline{c}_{k}(t)\right)$ can be thought of as summarizing the consumption preferences (which are independent of wealth or total spending), while the curvature of the transformation, $\Phi($.$) , reflects the degree of risk aversion. This separation of consumption$ preferences from risk aversion makes it possible to obtain simple statements about the level of the exchange rate in terms of the level of nominal spending, the level price and relative risk aversion. ${ }^{7}$

If the function $\Phi\left[u_{k}\left(\underline{c}_{k}(t)\right)\right]$ is at its maximum value given a consumption budget constraint, then $u_{k}\left(\underline{c}_{k}(t)\right)$ must also be at its maximum value subject to the same constraint. It is well known (see, for instance, Samuelson and Swamy (1974)) that the solution of the linearhomogenous problem,

$$
\mathrm{v}_{k}\left(\mathrm{M}_{\mathrm{k}}(\mathrm{t}), \underline{p}_{\mathrm{k}}(\mathrm{t})\right) \equiv \underset{\mathrm{c}_{\mathrm{kj}}(\mathrm{t})}{\operatorname{Max}}\left\{\mathrm{u}_{\mathrm{k}}\left(\underline{c}_{\mathrm{k}}(\mathrm{t})\right)-\lambda_{\mathrm{k}}(\mathrm{t})\left[\sum \mathrm{c}_{\mathrm{kj}}(\mathrm{t}) \mathrm{p}_{\mathrm{kj}}(\mathrm{t})-\mathrm{M}_{\mathrm{k}}(\mathrm{t})\right]\right\}
$$

\footnotetext{
${ }^{7}$ With non-homothetic utility, similar results can be obtained only in very special cases. One example of a tractable non-homothetic function is $U(t)=\left[\prod_{j=I}^{n}\left(c_{j}(t)-m_{j}\right)^{\alpha_{j}}\right]^{1-\eta}$, where risk aversion is a constant ( $\eta$ ) and the optimal consumption pattern depends on total spending and prices in a very straightforward way.
} 
is of the form $v_{k}(t)=M_{k}(t) / \Pi_{k}\left(p_{k}(t)\right)$. The function $\Pi_{k}\left(p_{k}(t)\right)$ is independent of nominal spending, $M_{k}(t)$, and is linear homogenous in the prices. Accordingly, $\Pi_{k}\left(\mathrm{p}_{k}(t)\right)$ is interpreted as the price level, and $v_{k}(t)=M_{k}(t) / \Pi_{k}\left(p_{k}(t)\right)$ is interpreted as real spending. These properties of homothetic functions lead to the following result:

Proposition 2: If utility functions are homothetic, the nominal exchange rate, $S(t)$, and the real exchange rate, $Z(t)$, are given by

$$
S(t)=\theta_{2} \frac{d \Phi_{2}(t) / d v_{2}(t)}{d \Phi_{1}(t) / d v_{1}(t)} \frac{\Pi_{1}(t)}{\Pi_{2}(t)}
$$

and

$$
Z(t) \equiv S(t) \frac{\Pi_{2}(t)}{\Pi_{1}(t)}=\theta_{2} \frac{d \Phi_{2}(t) / d v_{2}(t)}{d \Phi_{1}(t) / d v_{1}(t)}
$$

Proof: Using the relations $\mathrm{V}_{k}\left[\mathrm{M}_{k}(\mathrm{t}), \mathrm{p}_{\mathrm{k}}(\mathrm{t})\right]=\Phi_{\mathrm{k}}\left(\mathrm{v}_{\mathrm{k}}(\mathrm{t})\right)$ and $\mathrm{v}_{\mathrm{k}}(\mathrm{t})=\mathrm{M}_{\mathrm{k}}(\mathrm{t}) / \Pi_{k}(\mathrm{t})$, we can specify the marginal indirect utility of nominal spending as follows:

$$
\begin{aligned}
\frac{\partial V_{k}\left(M_{k}(t), p_{k}(t)\right)}{\partial M_{k}(t)} & =\frac{d \Phi_{k}\left(v_{k}(t)\right)}{d v_{k}(t)} \frac{\partial v_{k}(t)}{\partial M_{k}(t)} \\
& =\frac{d \Phi_{k}(v(t))}{d v_{k}(t)} \frac{1}{\Pi_{k}\left(p_{k}(t)\right)}
\end{aligned}
$$

Substituting (2.4) into (1.5) we obtain (2.2) and (2.3).

Corollary 1: The real exchange rate for country $k$ relative to country 1 is the MRS of that country's real spending, $v_{k}(t)$, relative to $v_{l}(t)$.

Proof: This result follows immediately from (2.3) and $\mathbf{U}()=\Phi_{1}\left(\mathrm{v}_{1}(\mathrm{t})\right)+\sum_{k=2}^{M} \Phi_{k}\left(v_{k}(t)\right)$

Corollary 2: If there are transaction costs or if consumption preferences differ, then for given net endowments the currencies of wealthier countries tend be overvalued by PPP standards.

Proof: From Corollary 1, we need to show that at the optimum, the MRS of $v_{2}(t)$ relative to $v_{1}(t)$ 
tends to be higher when $\theta_{2}$ is higher. The optimum is jointly determined by the indifference curves and the opportunity set. First consider the effect of initial wealths on the central planner's indifference curves. A higher initial wealth for country 2 generally implies a higher value for $\theta_{2}, 8$ which means that, in the $\left(v_{2}, v_{1}\right)$ plane, the indifference curves are more to the right, reflecting the bias in favor of country-2 consumption. For instance, in Figure 1 the curve through $\mathrm{V}^{\prime}$ corresponds to a higher value of $\theta_{2}$ than is the case for the curve through $\mathrm{V}$. Thus, for given endowments a higher initial wealth for country 2 will produce a higher MRS provided that the opportunity set is convex. We now show that the opportunity set is convex if (a) there are transaction costs or (b) consumption preferences differ across countries.

(a) The graph on the left in Figure 1 illustrates the case of one good and a proportional transaction cost equal to $\tau$, as in Dumas (1992). The bound on the consumption opportunity set is piece-wise linear: its slope is $-(1+\tau)$ when country 2 is importing (that is, when the consumption point $\mathrm{V}=$ $\left(v_{2}, v_{1}\right)$ is to the right and below the net endowment point $\left.Q=\left(q_{2}, q_{1}\right)\right)$, and its slope is $-1 /(1+\tau)$ when county 2 is exporting. Thus, the opportunity set is convex, and equilibria more to the right (like $\mathrm{V}^{\prime}$ relative to $\mathrm{V}$ ) correspond to a higher MRS and, therefore, a higher real exchange rate.

(b) The graph on the right illustrates the case of many commodities, no frictions, and different consumption preferences, $u_{k}\left(\underline{c}_{k}(t)\right)$. The problem of deriving the opportunity set for international real spending, $\left(\mathrm{v}_{1}, \mathrm{v}_{2}\right)$, is isomorphic to the problem of deriving a country's production opportunity set in the Heckscher-Ohlin model: the role of the Heckscher-Ohlin linear homogenous production functions with different factor intensities is taken over by the linear homogenous preference functions $u_{k}(c)$ with different consumption preferences; and the role of the factor endowments is taken over by the aggregate endowments, $q_{j}=q_{1 j}+q_{2 j}$, for each of the goods. Thus, with different consumption preferences the opportunity set is strictly convex. Therefore, the solution for a higher value of $\theta_{2}, V^{\prime}$, again results in a higher MRS than the solution for lower $\theta_{2}$,

\footnotetext{
${ }^{8}$ The one exception is discussed in Proposition 3(c).
} 
V.

The second corollary fits in with the stylized fact that currencies of richer countries tend to have higher real values. Thus, the effect of relative wealth (via $\left.\theta_{2}\right)$ complements the Balassa (1964)-Samuelson (1964) productivity-based explanation of the same empirical regularity.

\section{II.B. Purchasing Power Parity}

Much of the theory of exchange rates is based on PPP. In this section we discuss PPP as a special case of (2.2)-(2.3). In the next section we then derive a more general theory of the exchange rate that will provide an alternative hypothesis to PPP in our empirical tests.

The general model of the exchange rate in the case of homothetic preferences, (2.2)-(2.3), simplifies to relative PPP if the ratio of the marginal utilities of real spending is a constant. This will be the case under the alternative assumptions (a) and (b) listed in Proposition 3, below. Case (a) in the proposition corresponds to the standard (commodity-market based) set of assumptions for PPP. Case (b), being purely utility-based, is less familiar. Case (c)-the intersection of (a) and (b)-deserves special attention because this represents the sole case where relative wealths are not a determinant of the exchange rate.

\section{Proposition 3.}

(a) If commodity markets are frictionless and agents have identical, homothetic utility functions, then Absolute PPP holds.

(b) If agents have linear homogenous utility functions, the real exchange rate equals a constant, $\theta_{2},-$ that is, Relative PPP holds-irrespective of market imperfections and differences in consumption preferences.

(c) $\theta_{2}$ is independent of the initial wealths if and only if agents have identical linear homogenous utility functions and markets are perfect. Then $\theta_{2}=1$. 
Proof: To derive Proposition 3(a) from (2.3), note that under the assumptions of frictionless markets and identical homothetic utility functions, the relative consumption bundles will be identical across countries. That is, at any time $t$ there is but one composite good in the world (with time-varying composition proportional to the aggregate consumption amounts of the individual goods). It follows that at any moment the central planner's opportunity set in the $\left(v_{2}, v_{1}\right)$ plane is bounded by a minus 45 -degree line. Thus, if the optimum is an interior one, the MRS in that optimum always equals unity.

The proof of Proposition 3(b) immediately follows upon specifying $\Phi_{k}\left(v_{k}(t)\right)=v_{k}(t)$ in $(2.2): 9$

$$
\text { (risk-neutral model:) } \quad S(t)=\theta_{2} \frac{\Pi_{1}(t)}{\Pi_{2}(t)}
$$

To reconcile the if-part of Proposition 3(c) with Proposition 3(b), we need to show that $\theta_{2}$ must be equal to unity when preferences are identical and frictions are absent. This can be shown by contradiction. ${ }^{10}$ Under the assumptions of Proposition 3(c), the central planner's opportunity set is again bounded by a minus 45 -degree line. However, with risk neutrality-that is, $U(t)=v_{1}(t)+$ $\theta_{2} v_{2}(t)$ ) - the central planner's indifference curves degenerate to straight lines with slope $-\theta_{2}$. This geometry immediately means that, if $\theta_{2}$ were different from unity, there would always be a corner solution: one country would never consume anything, which is incompatible with the existence of two countries. To see why the irrelevance of initial wealths for the determination of exchange rates holds only under the highly stylized assumptions in part (c) of Proposition 3, just note that when there are transaction costs or when preferences differ across countries, the opportunity set is no

\footnotetext{
${ }^{9}$ This ignores possible constants (like $\Phi_{k}\left(v_{k}(t)\right)=a_{k} v_{k}(t)$ ); such constants are assumed to be part of $\theta_{k}$. See also footnote 5 .

${ }^{10}$ An alternative line of proof is as follows. Assume that there is one (composite) good, no friction, and that $\Phi_{k}\left(v_{k}(t)\right)=v_{k}(t)^{1-\eta}$ where $\eta(\neq 0)$ is relative risk aversion. It follows easily that the consumption ratio, $v_{2}(t) / v_{1}(t)$, will be constant and equal to $\theta_{2} 1 / \eta$. As a result, the ratio of initial wealths, $W_{2}(0) / W_{1}(0)$, must be $\theta_{2}{ }^{1 / \eta}$, too. This then means that $\theta_{2}$ equals $\left[W_{2}(0) / W_{1}(0)\right]^{\eta}$, which converges towards unity as $\eta$ approaches zero.
} 
longer linear (see Figure 1), while the indifference curves become non-linear when there is risk aversion. Either is sufficient to produce an interior solution. Thus, any value of $\theta_{2}$ then implies a well-defined sharing rule for consumption and, therefore, corresponds to a specific division of initial wealth.

We finish this section with two comments on Proposition 3. Our first comment relates to the perhaps puzzling indeterminacy of the central planner's consumption allocation problem in the case discussed in Proposition 3(c). Mathematically, this indeterminacy stems from the result that, under the assumptions in Proposition 3(c), all indifference curves must be minus 45-degree lines and, therefore, parallel to the budget line. To better understand the economics behind this indeterminacy, consider the portfolio decisions in the underlying decentralized economy. While, with identical preferences and perfect markets, consumption decisions are similar across countries, the portfolios held by the (risk-neutral) representative agents will differ unpredictably across countries. This is because, in equilibrium, all assets provide the same expected real return, which then implies that all fully invested portfolios are equally acceptable to a risk-neutral investor. Because of the indeterminacy of the portfolios chosen in the past, very little can be said about the allocation of consumption across countries at any given point in time. All we know is that the dividends will finance a consumption plan that clears the commodity markets. To reflect this indeterminacy, the central planner's indifference curves $U\left(v_{1}(t), v_{2}(t)\right)$ must rank all marketclearing consumption patterns $\left(v_{1}(t), v_{2}(t)\right)$ as equally desirable, regardless of the initial wealths. This means that the slope of the indifference curve, $\theta_{2}$, is equal to (minus) unity everywhere.

Second, note that Proposition 3 allows us to clear up some confusion that exists about the Unbiased Expectations Hypothesis (UEH) and the Siegel Paradox. Specifically, the Siegel Paradox seems to suggest that no equilibrium can be obtained in a risk-neutral world unless the 
exchange rate is non-random. ${ }^{11}$ To resolve the issue, we note first that risk-neutrality ought to be defined in real terms, not in nominal terms (as the UEH does). Stated differently, the UEH implicitly assumes that inflation is deterministic. But Proposition 3(b) tells us that, if inflation is known, the future spot rate automatically becomes non-random. Thus, under the assumptions of the UEH-risk-neutrality and no inflation risk - the Siegel Paradox does not arise, and there is no problem with obtaining equilibrium.

One implication of Proposition 3 is that, within the logic of standard micro-economics, variations in the real exchange rate are prima facie evidence of risk aversion when, at least, consumption preferences are homothetic. We shall address the implications of non-homothetic preferences in Section IV. Before that, we derive a testable equation for the level of the exchange rate in the homothetic/CRRA case, and present some empirical results.

\section{II.C Models with Constant Relative Risk Aversion}

Backus and Smith (1993), Dumas (1992), Stulz (1987), and Sercu et al. (1995) discuss models of the real exchange rate with one or two goods (whereof at least one good is tradable only at a cost), and constant relative risk aversion. These models are special cases of the general, homotheticutility model (2.2). To see this, we first consider the case where relative risk aversion is constant and not equal to unity; that is, we specify (2.2) for $\Phi_{k}\left(v_{k}(t)\right)=v_{k}(t)^{1-\eta_{k}}$, where $\eta_{k}$ is the PrattArrow measure of relative risk aversion. With this definition of $\Phi_{k}\left(v_{k}(t)\right)$, we obtain:

(CRRA model:) $S(t)=\theta_{2} \frac{1-\eta_{2}}{1-\eta_{1}} \frac{v_{2}(t)^{-\eta_{2}}}{v_{1}(t)^{-\eta_{1}}} \frac{\Pi_{1}(t)}{\Pi_{2}(t)}$

\footnotetext{
${ }^{11}$ Denote the forward rate, set at time $t$ for delivery at time $t+n$, by $F(t, t+n)$, and denote a conditional expectation about the future spot rate by $\mathrm{E}_{\mathrm{t}}(\mathrm{S}(\mathrm{t}+\mathrm{n}))$. The Siegel paradox is that, when exchange rates are uncertain, the UEH from country 1 's point of view is incompatible with the UEH from country 2's point of view: $F(t, t+1)=E_{t}(S(t+n))$ precludes $1 / F(t, t+1)=E_{l}(1 / S(t+n))$ unless $S(t+n)$ is non-random.
} 


$$
=\theta_{2} \frac{1-\eta_{2}}{1-\eta_{1}} \frac{M_{1}(t)^{\eta_{1}}}{M_{2}(t)^{\eta_{2}}} \frac{\Pi_{1}(t)^{1-\eta_{1}}}{\Pi_{2}(t)^{1-\eta_{2}}} .
$$

The last line follows after substituting $v_{k}(t)=M_{k}(t) / \Pi_{k}(t)$. In the log-utility case $(\eta=1)$, equation (1.5) immediately leads to

$$
\text { (Log-utility model:) } S(t)=\theta_{2} \frac{M_{1}(t)}{M_{2}(t)}
$$

Assuming two countries and identical relative risk aversions across countries, Sercu et al. (1995) derive (2.6) and (2.7) for the special case of one (imperfectly tradable) good, while Backus and Smith (1993) derive (2.6) for the case of CES consumption preferences defined over one perfectly tradable good and one non-tradable good. Stulz (1987) derives (2.7) from a two-country production economy with log investors that have identical, Cobb-Douglas preferences defined over a perfectly tradable good and a non-traded good. 12 Thus, we see that these special versions are easily generalized to cases where there are $\mathrm{N}$ goods (regardless of their degree of tradability) and M countries, and where the degrees of relative risk aversion and the commodity preferences differ across countries.

From Proposition 3(a), equations (2.6)-(2.7) collapse to Absolute PPP in the special case of identical consumption preferences and perfect commodity markets. Thus, unlike standard PPP theory, the CRRA model offers a specific equilibrium value for the exchange rate when there are frictions in the commodity markets or when consumption preferences differ. To characterize this equilibrium one needs just two additional (observable) variables, the nominal spendings. This means that we now have a specific alternative when we test for PPP. An additional advantage of the CRRA model is that it can be linearized by taking logs. Given the well-documented nonstationarity of the right-hand-side variables, this log-linearity of equations (2.6)-(2.7) also allows

\footnotetext{
${ }^{12}$ Stulz' exchange rate equation also contains interest rate terms: this is because he introduces money via the utility function rather than through a cash-in-advance constraint.
} 
us to use a cointegration framework rather than the less powerful techniques that rely on differencing the data. In the next section we discuss how one can test the alternative exchange rate models (PPP versus CRRA).

\section{II.D Testable Distinctions between the PPP and CRRA Models of the Exchange Rate}

In Sections II.B and II.C, both the CRRA and PPP models have been derived as exact relations. In practice, no proponent of PPP would reject that theory just because it does not hold perfectly at all times. Instead, the hypothesis is said to hold "in the long run". Once one admits deviations in the short run, the term "long-run PPP" obviously cannot mean that there are no deviations over long horizons; instead, "long-run PPP" can only mean that the ex ante variance of future deviations increases less than proportionally with the time horizon. Or, more precisely, "long-run PPP" is commonly equated with stationarity of the real exchange rate.

Tests of long-run PPP (in the above sense of the term) include time series analysis of real exchange rates and cointegration tests. The empirical evidence is mixed. Autocorrelation tests often cannot reject the hypothesis of a non-stationary real exchange rate (see, for instance, Adler and Lehman (1983)). However, the more powerful augmented Dickey-Fuller test does reveal mean reversion in real exchange rates (Abuaf and Jorion (1991)). Cointegration tests, on the other hand, tend to strongly reject PPP (see, for instance, Nessèn (1994) and the references therein).

In light of our theoretical analysis, we offer the following comments on these tests of PPP. First, the presence of mean-reversion in the real exchange rate does not allow us to distinguish between the PPP and CRRA models because the real exchange rate implied by (2.6)-(2.7) is likely to be stationary, too. To see this, re-cast model (2.6) in real terms:

$$
Z(t)=\theta_{2} \frac{1-\eta_{2}}{1-\eta_{1}} \frac{v_{2}(t)^{-\eta_{2}}}{v_{1}(t)^{-\eta_{1}}}
$$

It is quite likely that the real spending ratio on the right-hand side of (2.8) has finite variance. For 
instance, when all goods are tradable at a positive but finite cost and consumption preferences are identical across countries, then the relative real spending ratio in (2.8) is clearly bounded. Differences in spending patterns may lead to deviations from Relative PPP if, within each country, relative prices change over time. However, when productive resources can be redeployed across sectors, one would not expect relative prices to wander off to infinity or zero, within a country. Thus, relative price effects are not likely to imply martingale-behavior in the exchange rate either.

In light of the probable boundedness of the consumption ratio, stationarity of the real exchange rate is not a good criterion if the purpose is to distinguish between the PPP and CRRA models. Rather, the appropriate question is whether deviations from PPP are correlated with real spending data, with the direction of the correlation being consistent with our prior that $\eta_{k}$ is positive (and, almost always larger than unity). ${ }^{13}$ Alternatively, the question to be answered is whether, after controlling for nominal spending, the nominal exchange rate depreciates when domestic prices rise faster than foreign prices, rather than the inverse (as PPP predicts). This type of question is better addressed in a cointegration analysis rather than a univariate time series investigation of real exchange rates.

This then brings us to our second comment on empirical tests on PPP. True to their main purpose, standard cointegration tests have focused exclusively on the long-term relation between exchange rates and prices, and have simply taken for granted that no other variables are relevant in the VARs - the first stage of a cointegration analysis—or in the short-run dynamics in the final equation. Yet, PPP can also be obtained by setting $\eta_{k}=0$ in the CRRA model, (2.6); and this

\footnotetext{
${ }^{13}$ Following Lucas (1982), many have tested the CRRA model in the special case of equal $\eta$ 's. From equation (2.5), we see that there is no need to impose this restriction. For example, in a plot of means or standard deviations of $\log$ real rates against means or standard deviations of $\log$ ratios of real spending ratios, Backus and Smith (1993) find no linear pattern. Such a finding, being consistent with differences in $\eta$ 's across countries, is not evidence against the general CRRA model, and a fortiori not against the equilibrium approach to the exchange rate.
} 
CRRA model predicts a long-run relationship between not just exchange rates and prices but also nominal spendings:

$$
\left.\log S(t)=\log \left(\theta_{2} \frac{1-\eta_{1}}{1-\eta_{2}}\right)+\eta_{1} \log M_{1}(t)-\eta_{2} \log M_{2}(t)\right)+\left(1-\eta_{1}\right) \log \Pi_{1}(t)-\left(1-\eta_{2}\right) \log \Pi_{2}(t)
$$

In estimating (2.9) in its general form (without a priori restricting the $\eta$ 's to be zero), both nominal spendings and prices are allowed to play independent roles in the short-term dynamics. Thus, when testing for PPP as a special case of (2.9), the first-pass VARs and the short-term fluctuations are not the same as in the standard cointegration test of PPP (where spending is not allowed to play any role). We provide evidence, in the next section, that such differences in the modeling do affect the conclusions regarding PPP. As a theory of exchange rates, PPP of course cannot answer the question which variables should enter the short-term model, because PPP is utterly agnostic about what variables explain movements of the real rate within the leeway provided by market imperfections or differences in consumption preferences.

Note that a similar VAR-modeling decision has to be made when the CRRA model is to be analyzed. Again, theory has no suggestions about what explains short-term deviations from the equilibrium because theory derives (2.8)-(2.9) as an exact relation. The pragmatic solution again is to assume that the short-term fluctuations are driven only by the variables entering the long-term cointegration relation. But even within this assumption two approaches are possible. First, one could work with (2.9), which lists five nominal variables; then the assumption is that the nominal prices and spendings are allowed to independently affect the short-run fluctuations of the exchange rate. Alternatively, one could re-cast (2.9) into real terms, as follows:

$$
S_{2}(t) \frac{\Pi_{1}(t)}{\Pi_{2}(t)}=\log \left(\theta_{2} \frac{1-\eta_{1}}{1-\eta_{2}}\right)+\eta_{2} \log \frac{M_{2}(t)}{\Pi_{2}(t)}-\eta_{1} \log \frac{M_{1}(t)}{\Pi_{1}(t)}
$$

In estimating the cointegration vector(s) between the real exchange rate and the real spending variables in (2.10), one then assumes that also for the first-pass VARs and the short-run dynamics 
the real consumption data suffice; that is, unlike in tests of model (2.9) one now constrains the coefficients of $\log M_{j}(t)$ and $\log \Pi_{j}(t)$ to be the same (up to the sign) in the long-run cointegration relationship, and likewise in the short-run fluctuations. Again, it is not a priori obvious which way of specifying the VARs and the short-run dynamics is the correct one.

To summarize: univariate tests of stationarity of the real exchange rate do not allow us to distinguish between the PPP and CRRA models of the exchange rate. As to cointegration tests, we can test the following hypotheses:

- Hypothesis PPP(1) - the standard cointegration test of PPP: the data are compatible with the hypothesis $\eta_{\mathrm{k}}=0$ for all countries $\mathrm{k}$, and the short-term dynamics involve only inflation rates.

- Hypothesis PPP(2): the data are compatible with the hypothesis $\eta_{k}=0$ for all countries $k$, and the short-term dynamics involve both inflation rates and changes in nominal spending.

- Hypothesis PPP(3): in the long run, the real exchange rate is unrelated to real spending data, and the short-term dynamics involve only changes in real spending.

- Hypothesis CRRA(1): the data are compatible with the hypothesis $\eta_{k}>0$ for all countries $k$, and the short-term dynamics involve both inflation rates and changes in nominal spending.

- Hypothesis CRRA(2): the data are compatible with the hypothesis $\eta_{k}>0$ for all countries $k$, and the short-term dynamics involve only changes in real spending.

Note, lastly, that the power of such cointegration tests may be low. Assume, for instance, that the CRRA model is true, and that one tests Hypothesis PPP(1), which omits the nominal spending variables. One could still observe a PPP-like relation between the exchange rate and the domestic and foreign price level if each of the omitted nominal-spending variables is highly positively correlated with the price level of the corresponding country. For instance, under hyperinflation circumstances, the log of a country's nominal spending closely tracks the log of that country's price level; thus, under those circumstances the estimated coefficient for the price level 
can be expected to be close to unity because this coefficient is likely to add (most of) the effect of nominal spending, $\eta_{k}$, to the ceteris paribus effect of the price level, which equals 1- $\eta_{k}$. This argument also implies that, when the CRRA model holds and the sample paths of prices and nominal spendings are sufficiently similar, it can be quite hard to distinguish between Hypothesis $\operatorname{PPP}(2)$ and Hypothesis CRRA(1).

\section{Empirical Tests of the Model with Homothetic Utility and Constant Relative Risk Aversion}

In this section, we test the CRRA model (in its log form, equations (2.9)-(2.10)) using cointegration analysis. ${ }^{14}$ The original Engle and Granger (1987) cointegration approach adopts a bivariate framework, while the more recent and more powerful approach developed in Johansen (1991) uses a multivariate framework that allows for the existence of multiple cointegrating vectors and a richer specification of short-run dynamics. We have used the latter approach, and in particular the type of tests described in Johansen and Juselius (1992), to implement the empirical tests of the PPP and CRRA models.

\section{A. Data, Model Setup, and Estimation Procedure}

One problem with (2.9)-(2.10) is that, for many countries, real consumption data are not available in high-frequency form. As the VAR procedure used in cointegration analysis requires a large number of observations, we introduce another restriction: nominal spending is assumed to be cointegrated with the money supply. One case where this is trivially true is the cash-in-advance

\footnotetext{
${ }^{14}$ Cointegration analysis was pioneered by Granger(1981) and developed by, among others, Engle and Granger (1987), Phillips (1990), Stock and Watson (1988) and more recently by Johansen (1988,1991) and Johansen and Juselius (1990,1992). A lucid and relatively non-technical exposition of the main ideas can be found in Dickey and Rossana(1994).
} 
world, where a country's nominal spending simply equals the country's money supply. Consumer price indices being available on a monthly basis, the substitution of money supplies for nominal consumption data allows us to use monthly data.

Thus, our main purpose is to test (a) whether there exists a long-run equilibrium relationship between nominal exchange rate, price levels and money supplies, and (b) whether such a relationship, if any, is of the form specified in equation (2.9)-(2.10) with acceptable positive values for the risk aversion parameters $\eta_{1}$ and $\eta_{2}$. We will contrast this test of the CRRA model against the classical PPP alternative, the special case of (2.9)-(2.10) with zero risk aversions.

We have selected six countries. The US serves as the reference country. Germany (GE), the United Kingdom (UK) and Japan (JP) are chosen so as to represent the most heavily traded currencies. Lastly, we added two smaller European countries, Belgium (BE) and Switzerland (SW), on the basis that they (a) had an exchange rate that moved sufficiently independently from the DEM, (b) did not no exchange controls during the post-Bretton-Woods era, and (c) had complete data in the International Financial Statistics tape published by the IMF: . The data set consists of seventeen series of monthly data on nominal exchange rates of these five countries' currencies against the US dollar, the consumer price indices (CPIs) of the six countries, and their nominal money stocks $\left(\mathrm{M}_{0} ; \mathrm{M}_{3}\right.$ for the UK). The sample period is from January 1973 to December 1992.

The data are arranged into a matrix that depends on which model is being tested. Denoting logs of $S_{k}, M_{k}$, and $\Pi_{k}$ by $s_{k}, m_{k}$, and $p_{k}$, respectively, and denoting the log real exchange rates and money supplies by $s_{\mathrm{k}}^{*}$ and $\mathrm{m}_{\mathrm{k}}^{*}$, the data matrices are:

- for Hypothesis PPP(1): the 11-variable system

$\left[\mathrm{s}_{\mathrm{BE}}, \mathrm{s}_{\mathrm{SW}}, \mathrm{s}_{\mathrm{GE}}, \mathrm{s}_{\mathrm{GB}}, \mathrm{s}_{\mathrm{JP}}, \mathrm{p}_{\mathrm{BE}}, \mathrm{p}_{\mathrm{SW}}, \mathrm{p}_{\mathrm{GE}}, \mathrm{p}_{\mathrm{GB}}, \mathrm{pJP}_{\mathrm{J}}, \mathrm{p}_{\mathrm{US}}\right]$

- for Hypotheses PPP(2) and CRRA(1): the 17-variable system 
$\left[s_{B E}, s_{S W}, s_{G E}, s_{G B}, s_{J P}, p_{B E}, p_{S W}, p_{G E}, p_{G B}, p_{J P}, p_{U S}, m_{B E}, m_{S W}, m_{G E}, m_{G B}, m_{J P}, m_{U S}\right] ;$

- for Hypotheses PPP(3) and CRRA(2): the 11-variable system

$\left[s_{\mathrm{BE}}^{*}, \mathrm{~s}_{\mathrm{SW}}^{*}, \mathrm{~s}_{\mathrm{GE}}^{*}, \mathrm{~s}_{\mathrm{GB}}^{*}, \mathrm{~s}_{\mathrm{JP}}^{*}, \mathrm{~m}_{\mathrm{BE}}^{*}, \mathrm{~m}_{\mathrm{SW}}^{*}, \mathrm{~m}_{\mathrm{GE}}^{*}, \mathrm{~m}_{\mathrm{GB}}^{*}, \mathrm{~m}_{\mathrm{JP}}^{*}, \mathrm{~m}_{\mathrm{U}}^{*}\right]$.

For each data set we first test how many long-run relationships seem to be present. The CRRA(1)-(2) and PPP(1)-(2) hypotheses predict that there should be at least five of these cointegrating vectors; but given the nature of the underlying variables and the degree of interdependence (and possibly policy coordination) among the countries in the sample, the existence of a larger number of cointegration relations is quite likely. To estimate the number of cointegrating relationships we use the maximum-eigenvalue $\left(\mathrm{L}_{\max }\right)$ and the trace statistics. ${ }^{15}$

Having established that there are at least five long-run relationships, we then verify the statistical acceptability of the $\operatorname{PPP}(1)$ hypothesis in the first 11 -variable data set. This test is first done one country at the time, and then for all countries simultaneously. The country-by-country test is undertaken as follows. In the first 11-series system (the test of Hypothesis PPP(1)), for instance, the hypothesis is that, for Belgium, the coefficients for $\mathrm{s}_{\mathrm{BE}}, \pi_{\mathrm{BE}}$ and $\pi_{\mathrm{US}}$ are $1,-1$, and 1 , respectively. To test the acceptability of Hypothesis PPP(1) for Belgium, we verify whether the $11 \times 1$ matrix $\beta_{\mathrm{PPP}}=\left[\begin{array}{llllllllll}1 & 0 & 0 & 0 & 0 & -1 & 0 & 0 & 0 & 0\end{array}\right]^{\prime}$ is compatible with the data, imposing no restrictions on the remaining cointegrating vectors. Such country-by-country tests are done for each of the other countries. The second test is whether the hypothesis is acceptable for all five countries simultaneously. In this test, five cointegrating vectors are specified to conform to the PPP-

${ }^{15} \mathrm{~L}_{\max }=-\mathrm{T} \log \left(1-\mathrm{L}_{\mathrm{T}+1}\right)$ and $\mathrm{TR}=-\mathrm{T} \sum_{\mathrm{i}=\mathrm{r}+1}^{\mathrm{p}} \log \left(1-\mathrm{L}_{\mathrm{i}}\right)$, where $\mathrm{T}$ is the sample size, $\mathrm{p}$ the number of variables, and $L_{i}$ is the $i$-th ordered eigenvalue. The $L_{\max }$ statistic tests the hypothesis that there are $r(\leq$ p-1) cointegration relations against the alternative that there are $r+1$ such relations. The trace statistic tests the hypothesis that there are $r(<p)$ cointegration relations against the alternative that there are $p$ such relations. The tests often yield different conclusions. Osterwald-Lenum (1992) provides critical values for $p=11$ variables, so that $(p-r)$ can go from $0(r=11)$ to $11(r=0)$. Because these tests are known to have low power, Johansen and Juselius (1992) recommend using $90 \%$ critical values rather than the usual $95 \%$. 
hypothesis, while the remaining vectors are left unrestricted. The test statistic is a likelihood ratio.

Tests of the PPP(2) and CRRA(1) hypotheses (in the 17-variable system) are analogous: we test for the presence of a specific cointegrating relation as suggested by (2.9). In a test of a PPP hypothesis as reported above, the choice of coefficients for $s_{k}, p_{k}$ and pus - $[1,-1,1]-$ is dictated by theory. Under the CRRA hypotheses, however, any positive value of $\eta_{U S}$ and $\eta_{k}$ is permissible. Consequently, the number of theoretically acceptable cointegration vectors is infinitely large. We report the tests for some illustrative values for these parameters, first imposing the restriction one country at a time, and then for all five countries simultaneously. For instance, to test the hypothesis for Deutsche Mark we test whether the following vector is acceptable for the preselected values for $\eta_{G E}$ and $\eta_{U S}$ :

$$
\left[0,0,1,0,0,0,0,-\left(1-\eta_{\mathrm{GE}}\right), 0,0,\left(1-\eta_{\mathrm{US}}\right), 0,0,-\eta_{\mathrm{GE}}, 0,0, \eta_{\mathrm{US}}\right]
$$

\section{III.B. Empirical Results and Tests of Hypotheses}

We first verify the presence of unit roots in the log of the time series of $S(t), \Pi(t)$ and $M(t)$. Table 1, below, presents the results of applying the augmented Dickey-Fuller (ADF) t-test with a data generating process that allows for both constant and a trend. There is a unit root present in all the data series, except for the Swiss and US money supply series which may be stationary (apart from the time trend). Tests for the presence of more than one unit root were also performed but failed to reveal the presence of another unit root in any of the variables included in the system. The cointegration procedure itself was implemented with CATS in RATS. ${ }^{16}$ The lag length in the first set of auxiliary regressions was increased until the Box-Ljung statistic for serial correlation among residuals was insignificant at $5 \%$ level for all the equations. The final value of $k$ was 10 .

\footnotetext{
${ }^{16}$ Hansen, H. and K. Juselius (1995): CATS in RATS Cointegration Analysis of Time Series.
} 
To test Hypothesis PPP(1), we estimate the cointegration relations in a system consisting of five nominal exchange rates and six price levels. This is the usual set-up for tests of bilateral PPP in a multivariate cointegration framework. Table 2 presents the results for the number of cointegrating relationships in the data. At the $10 \%$ level of significance, both the $\mathrm{L}_{\max }$ and trace tests indicate the presence of nine cointegrating relations among the eleven variables. This is consistent with PPP, which predicts that there should be at least five cointegration relations in the data set.

Table 3 presents the results of the likelihood ratio tests for the PPP(1) hypothesis. Our results confirm the findings of Nessèn (1994) and others: in the exchange rate/prices system the hypothesis of stationarity of real exchange rates is rejected for all currencies, whether we test for all five countries individually or simultaneously. The only exception is the country-by-country test for Belgium, where the hypothesis of a stationary real rate vis-à-vis the US receives weak support from the data.

We next analyze the 17-variable system with five nominal exchange rates, six price levels and six money stocks. Again, the first step is to estimate the number of cointegrating relationships. The exchange rate model implies that there should be at least five of these relations among the six countries. Table 4 presents the trace and maximal eigenvalue statistics that test for the number of cointegrating vectors. From the table it is clear that the data reveal sixteen cointegrating relations among the seventeen variables.

In this 17-variable system we now test the hypothesis CRRA(1) and $\operatorname{PPP}(2)$; that is, we test for the presence of a specific cointegrating relation for each currency involving (only) the following variables: that currency's nominal exchange rate, the price level and money stock of the country and price level and money stock of the reference country (the US). As argued before, the number of theoretically acceptable values of $\eta_{U S}, \eta_{B E}, \eta_{S W}, \eta_{U K}, \eta_{G E}$, and $\eta_{J P}$ is infinite, so that we can only show some representative cases. Table 5 presents the results for four different 
combinations of $\eta$-values: $\left(\eta_{U S}, \eta_{\text {non-US }}\right)=(1.25,1.50),(0.6,0.4),(0.05,0.05)$, and $(0,0)$. The $(0,0)$ combination is the test of the $\operatorname{PPP}(2)$ hypothesis, which differs from the first PPP-test in that we now allow money supplies to play a role in the short-term dynamics.

From Table 5 we see that each of the proposed cointegration vectors is still rejected when imposed for all countries simultaneously. However, and unlike what we found in the tests of Hypothesis PPP(1), each of these hypotheses now becomes acceptable when tested one country at the time-with the single exception for Switzerland in the case ( $\left.\eta_{U S}, \eta_{2}\right)=(1.25,1.50)$. The conclusion is twofold. First, money supplies seem to play a role in the short term dynamics process. Second, when allowing for this role of money supplies, it becomes difficult to reject any low value for relative risk-aversion (including, disappointingly, zero risk aversion). Apparently, the money supply and price data are too similar, which causes problems if, as the model suggests, the corresponding coefficients, $\eta_{\mathrm{k}}$ and $1-\eta_{\mathrm{k}}$, sum to unity. ${ }^{17}$

As discussed before, equation (2.9) can also be interpreted as an equilibrium relation between the bilateral real exchange rate of currency $i$ versus the reference currency and the corresponding real money stocks, equation (2.10). To test the validity of such a relation we now estimate a multivariate system with five real exchange rates and six real money stocks, and we test for the presence of cointegration vectors involving $\log \left(S_{\mathrm{i}} \Pi_{\mathrm{i}} / \Pi_{\mathrm{US}}\right), \log \left(\mathrm{M}_{\mathrm{i}} / \Pi_{\mathrm{i}}\right)$ and $\log \left(\mathrm{M}_{\mathrm{US}} / \Pi_{\mathrm{US}}\right)$. This test has the advantage of restricting, a priori, the coefficients of $\log \left(\mathrm{M}_{\mathrm{i}}\right)$ and $\log \left(\Pi_{\mathrm{i}}\right)$ to sum to unity, and, thus, to steer clear of the multicolinearity between the two series. The disadvantage is that, now, nominal money stocks and price levels are no longer allowed to play an independent role in the short-term dynamics either; that is, the short-run fluctuations in the real exchange rate are assumed to be driven by real money supplies only.

\footnotetext{
${ }^{17}$ Mark (1985), who tests the relationship between interest rates and marginal rates of substitution, also obtains very imprecise estimates of $\eta$ and cannot reject the hypothesis that $\eta=0$.
} 
Table 6 provides the results of tests for the number of cointegrating vectors in this 11 variable system. The CRRA(2) model says that there should be at least five cointegrating relationships in the real data. In contrast, the PPP(3) hypothesis implies that there should be at most nine. This is because, in the PPP view (as distinct from CRRA) the real rate is not related, in the long run, to real spending variables, which then implies that all cointegrating relationships must be either among the real exchange rates themselves-up to four cointegration relationships-or among the real spending variables-up to five cointegration relationships. The $L_{\max }$ test indicates presence of seven cointegrating vectors while the trace test suggests eight. In the further tests of the CRRA(2) hypothesis we have proceeded on the assumption that there are seven cointegrating relations.

As before, we have tested the acceptability of a large number of specific cointegration vectors corresponding to selected values for the risk aversion parameters. Some representative results are shown in Table 7. Each of the proposed vectors in Table 7 is now rejected, with the possible exception of the vector ( $\eta_{U S}=3, \eta_{\mathrm{BE}}=2$ ) for the Belgian Franc. To confirm the generality of this negative conclusion we add, in the last panel of Table 7 , a test where we do not specify any numerical values for the parameters $\eta_{i}$ and $\eta_{U S}$; that is, we only wish to test whether there is a cointegrating relationship that involves $\log \left(\mathrm{S}_{\mathrm{i}} \Pi_{\mathrm{i}} / \Pi_{\mathrm{US}}\right), \log \left(\mathrm{M}_{\mathrm{i}} / \Pi_{\mathrm{i}}\right)$ and $\log \left(\mathrm{M}_{\mathrm{US}} / \Pi_{\mathrm{US}}\right)$, and only these variables. This restriction is rejected in all cases except, very marginally, for the Belgian franc.

We summarize our empirical findings as follows. First, nominal money stocks and prices do seem to play separate roles in the short-term dynamics: the data reject all models where only real money supplies are allowed to play a role in the short-run fluctuations or where nominal money is not allowed to play any role in them. Second, when money supplies and prices are allowed to play a separate role in the short-term dynamics, equation (2.9) is acceptable when tested one country at the time, as long as the proposed degree of risk aversion is low or even zero. This 
finding is consistent with the combined hypothesis that the CRRA model holds and that money and price data follow similar time paths. Indeed, the CRRA model predicts that the coefficients for the price and money supply variables sum to unity; so when these series behave rather similarly over time, it is difficult to distinguish between the roles of the two variables.

Still, the evidence in favor of the CRRA model is far from conclusive. One possible reason for the less than satisfactory results may be the model's assumptions of homothetic preferences and constant risk aversion. In the following section, we therefore return to the general model (1.5) and see what can be said about (changes in) exchange rates when preferences are not assumed to be homothetic and risk-aversion is not constant.

\section{Characterizing Changes in the Exchange Rate}

From equation (1.5), it follows that percentage changes in the nominal exchange rate reflect percentage changes in the marginal utilities of spending: ${ }^{18}$

$$
\frac{\mathrm{dS}}{\mathrm{S}}=\frac{\mathrm{d} \Lambda_{2}}{\Lambda_{2}}-\frac{\mathrm{d} \Lambda_{1}}{\Lambda_{1}}
$$

As in, for instance, Barten (1964) or Breeden (1978), we now apply a Slutsky decomposition of the changes in the marginal indirect utilities. That is, we decompose $d \Lambda / \Lambda$ into the effect of the curvature of the indirect utility (the degree of relative risk aversion) and the effects of changes in each of the arguments of the indirect utility. As a result, the change in the nominal exchange rate is given by the sum of two terms: one, the international differences in real consumption growth rates weighted by each country's relative risk aversion, and two, the international difference in the

\footnotetext{
${ }^{18}$ Equation (4.1) is a first-order approximation. A (second-order) Ito expansion shows that, in a model with continuous time and continuous but stochastic output processes, there will be a drift added to the right hand side of (4.1) that depends on the risk aversions and the (co)variances of the nominal spendings, the marginal inflation rates, and the total inflation rates.
} 
marginal inflation rates:

Proposition 4: The change in the nominal exchange rate, to a first-order approximation, is

$$
\frac{\mathrm{d} S}{S}=\eta_{1}(\mathrm{t})\left(\frac{\mathrm{d} M_{1}}{M_{1}}-\frac{d \Pi_{1}}{\Pi_{1}}\right)-\eta_{2}(t)\left(\frac{d M_{2}}{M_{2}}-\frac{d \Pi_{2}}{\Pi_{2}}\right)+\frac{d \pi_{1}}{\pi_{1}}-\frac{d \pi_{2}}{\pi_{2}},
$$

where

$$
\begin{aligned}
& \eta(t)=\frac{-M_{k} \partial^{2} V_{k} / \partial M_{k}{ }^{2}}{\partial V_{k} / \partial M_{k}} \text { is the degree of relative risk aversion, }{ }^{19} \\
& \frac{\mathrm{d} \Pi_{k}}{\Pi_{k}}=\sum_{j=1}^{N}\left[\frac{c_{k j} p_{k j}}{M_{k}}\right] \frac{d p_{k j}}{P_{k j}} \text { is inflation weighted on the basis of average consumption, and } \\
& \frac{\mathrm{d} \pi_{k}}{\pi_{k}}=\sum_{j=1}^{N}\left[\frac{\partial c_{k j}}{\partial M_{k}} P_{k j}\right] \frac{d p_{k j}}{P_{k j}} \text { is inflation weighted on the basis of marginal consumption. }{ }^{20}
\end{aligned}
$$

Proof: We start from the total differential of $\Lambda_{k}=\Lambda_{k}\left(M_{k}, p_{k}\right)$, substitute the definition $\Lambda_{k}=$ $\partial \mathrm{V}_{\mathrm{k}}\left(\mathrm{M}_{\mathrm{k}}, \mathrm{p}_{\mathrm{k}}\right) / \partial \mathrm{M}_{\mathrm{k}}$, invoke Roy's Identity $-\partial \mathrm{V}_{\mathrm{k}} / \partial \mathrm{p}_{\mathrm{kj}}=-\mathrm{c}_{\mathrm{kj}} \partial \mathrm{V}_{\mathrm{k}} / \partial \mathrm{M}_{\mathrm{k}}$, and use the rule for differentiating a product. Finally, we bring out the percentage changes in the budget and the prices, and rearrange:

$$
\begin{aligned}
\frac{\mathrm{d} \Lambda_{k}}{\Lambda_{k}} & =\frac{1}{\Lambda_{k}}\left[\frac{\partial \Lambda_{k}}{\partial M_{k}} d M_{k}+\sum_{j=1}^{N} \frac{\partial \Lambda_{k}}{\partial p_{k j}} d p_{k j}\right] \\
& =\frac{1}{\partial V_{k} / \partial M_{k}}\left[\frac{\partial^{2} V_{k}}{\partial M_{k}{ }^{2}} d M_{k}+\sum_{j=1}^{N} \frac{\partial^{2} V_{k}}{\partial p_{k j} \partial M_{k}} d p_{k j}\right]
\end{aligned}
$$

\footnotetext{
${ }^{19}$ This definition of relative risk aversion, also adopted by Breeden (1978), is a 'real' measure of relative risk aversion because, when taking partial derivatives with respect to $m_{k}(t)$, we hold constant the prices. In the one-good case, for instance, this definition is identical to the standard definition, $-c_{k}$ $\left[\partial^{2} U_{k} / d c_{k}^{2}\right] /\left[\partial U_{k} / d c_{k}\right]$.

${ }^{20}$ The marginal weights, $\left[\partial c_{\mathrm{kj}} / \partial \mathrm{m}_{\mathrm{k}}\right] \mathrm{p}_{\mathrm{kj}}$, sum to unity by virtue of the budget constraint. We denote the two inflation rates by $d \pi_{k} / \pi_{k}$ and $d \Pi_{k} / \Pi_{k}$ for consistency with the notation in the previous section, but we do not wish to imply that the integrated counterparts $\pi_{k}$ and $\Pi_{k}$ always have known closed-form solutions.
} 


$$
\begin{aligned}
& =\frac{1}{\partial V_{k} / \partial M_{k}}\left[\frac{\partial^{2} V_{k}}{\partial M_{k}^{2}} d M_{k}-\sum_{j=1}^{N} \frac{\partial \frac{\partial V_{k}}{\partial M_{k}} c_{k j}}{\partial M_{k}} d_{p_{k j}}\right] \\
& =\frac{1}{\partial V_{k} / \partial M_{k}}\left[\frac{\partial^{2} V_{k}}{\partial M_{k}^{2}} d M_{k}-\sum_{j=1}^{N}\left(\frac{\partial^{2} V_{k}}{\partial M_{k}^{2}} c_{k j}+\frac{\partial V_{k}}{\partial M_{k}} \frac{\partial c_{k j}}{\partial M_{k}}\right) d P k j\right] \\
& =-\frac{-M_{k} \partial^{2} V_{k} / \partial M_{k}^{2}}{\partial V_{k} / \partial M_{k}}\left[\frac{d M_{k}}{M_{k}}-\sum_{j=1}^{N} \frac{c_{k j} p_{k j}}{M_{k}} \frac{d p_{k j}}{p_{k j}}\right]-\sum_{j=1}^{N} \frac{\partial c_{k j}}{\partial M_{k}} p_{k j} \frac{d p_{k j}}{p_{k j}} \\
& =-\eta(t)\left[\frac{d M_{k}}{M_{k}}-\frac{d \Pi_{k}}{\Pi_{k}}\right]-\frac{d \pi_{k}}{\pi_{k}}
\end{aligned}
$$

Substitution of (4.3) into (4.1) then immediately produces (4.2).

To detect the importance of non-homothetic-preferences and time-varying risk aversion for the purpose of describing short-run changes of exchange rates, we can compare Equation (4.2) to the log-change version of the homothecy/CRRA Model in equation (2.6):

$$
\frac{\mathrm{d} S}{S}=\eta_{1} \frac{\mathrm{d} M_{1}}{M_{1}}-\eta_{2} \frac{d M_{2}}{M_{2}}+\left(1-\eta_{1}\right) \frac{d \Pi_{1}}{\Pi_{1}}-\left(1-\eta_{2}\right) \frac{d \Pi_{2}}{\Pi_{2}} .
$$

Thus, locally, the non-constancy of relative risk aversion has no first-order effects, but nonhomothetic-preferences do. Specifically, the marginal and total inflation rates no longer coincide, and the term $\left(1-\eta_{\mathrm{k}}\right) \mathrm{d} \Pi_{\mathrm{k}} / \Pi_{\mathrm{k}}$ in (4.4) needs to be replaced by $\mathrm{d} \pi_{\mathrm{k}} / \pi_{\mathrm{k}}-\eta_{\mathrm{k}} \mathrm{d} \Pi_{\mathrm{k}} / \Pi_{\mathrm{k}}$. A related implication of (4.3) is that risk-neutrality is not sufficient to obtain PPP (Proposition 3). Specifically, when $\eta=0$, the exchange rate change generally equals the marginal inflation differential; and only in the case of homothetic preferences will marginal inflation coincide with average inflation.

Equation (4.2) also explains the poor results of regression tests of Relative PPP. To see this, first consider the special case where preferences are homothetic and relative risk aversion is equal and constant. Under these conditions, (4.2) simplifies to: 


$$
\frac{\mathrm{dS}}{\mathrm{S}}=\eta\left(\frac{\mathrm{dM}_{1}}{\mathrm{M}_{1}}-\frac{\mathrm{dM}_{2}}{\mathrm{M}_{2}}\right)+(1-\eta)\left(\frac{\mathrm{d} \Pi_{1}}{\Pi_{1}}-\frac{\mathrm{d} \Pi_{2}}{\Pi_{2}}\right)
$$

The implications of (4.4) for tests of relative PPP are similar to the inferences made in the singlegood model of Sercu et al. (1995). An increase in domestic inflation should lead to an appreciation of the home currency (a decrease in S), as long as we control for nominal spending. In light of this, the puzzle in standard regression tests of relative PPP is not why we do not observe exchange rates that are equal, on average, to inflation differences. Rather, given that $\eta$ is commonly accepted to be larger than unity, the puzzle is why we often observe a positive association between the two at all. The reason may be that, in the standard regression tests of relative PPP, the nominal spending variables are omitted. Given that growth rates of nominal spending are positively correlated with inflation rates, the true (negative) effect, $1-\eta$, of inflation is to some extent confounded with the positive effect, $\eta$, of the omitted spending variable. As a result, the empirical estimates of the regression slope of $\Delta \ln S$ on $\Delta \ln \left(\Pi_{1} / \Pi_{2}\right)$ are biased towards unity. As Sercu $e t$ al. (1995) argue, this is especially true in low-frequency data and in samples drawn from periods of hyperinflation where the correlation between growth in nominal spending and inflation is likely to be stronger than otherwise. This conclusion also holds if $\eta$ differs across countries.

Equation (4.2) also provides some insights about regression tests of relative PPP that cannot be obtained from (4.4). One, in the (realistic) case where preferences are non-homothetic, there is an additional omitted variable, marginal inflation, which is imperfectly proxied for by the CPI measure of inflation. Since $d \Pi_{k}(t) / \Pi_{k}(t)$ is an imperfect proxy for $d \pi_{k}(t) / \pi_{k}(t)$, the coefficient for CPI inflation in a regression of $\Delta \ln S$ on $\Delta \ln \Pi_{l} / \Pi_{k}$ is expected to be closer to zero than in the homothetic case. Two, in the regression (4.4), the coefficients for the true inflation rates and the growths in nominal spending need not be identical across countries because the degree of risk aversion need not be equal across countries. ${ }^{21}$ Imposing a single coefficient for $\Delta \ln \left(M_{1}\right)$ and

\footnotetext{
${ }^{21}$ In their regression tests of relative PPP, Apte, Kane, and Sercu (1994) allow for different coefficients across countries, and they test for equality. The only instances where the equality hypothesis is not
} 
$-\Delta \ln \left(M_{2}\right)$ will produce estimates that are neither equal to $\eta_{1}$ nor to $\eta_{2}$ (and likewise for the inflation terms). Three, the risk aversion coefficients need not be constant over time. Thus, the standard constant-coefficient regression test for PPP may be inappropriate. In view of all this, the poor results that are commonly obtained in regression tests of relative PPP may simply be the result of misspecification of the test equation rather than some kind of excess volatility or irrationality. 22

Equation (4.2) has similar implications for cointegration tests of exchange rate models: The tests presented in Section III suffer from a missing-variable bias, and the fixed-coefficient approach may be inappropriate. In addition, like the homothecy/CRRA-model, equation (4.2) is still consistent with PPP-like behavior in the long run, especially in high-inflation samples: If longrun cumulative marginal inflation rates follow similar time paths as cumulative average inflation rates and money supply data, it will again be difficult to distinguish between the roles of these three variables if, as Proposition 4 predicts, the true coefficients of the three variables sum to unity. Thus, the fact that the country-by-country tests of Section III appear to accept a rather wide range of risk-aversion parameters can also be consistent with the generalized model in equation (4.2).

\section{Conclusion}

Much of the literature on exchange rate determination is based on PPP, with PPP being justified on the basis of the consumption opportunity set (frictionless commodity arbitrage). In contrast, the standard micro-economics paradigm views relative prices-and, hence, also exchange rates-as jointly determined by consumption opportunity sets and preferences. We accordingly characterize the equilibrium exchange rate in a general equilibrium economy with imperfect commodity

rejected is when the power of the test is low.

2 See the survey article by Frankel and Rose (1994) for the evidence on bubbles in exchange rates. 
markets. We can avoid strong restrictions on the output processes or on preferences because, for our purpose, there is no need to specify the link between the exchange rate and the underlying exogenous variables. In such a model, the real exchange rate is determined by differences in initial wealths - the currencies of richer countries tend to be overvalued, by PPP standards-and by differences in marginal utilities of total consumption. In the special case of homothetic Constant Relative Risk Aversion (CRRA) utility functions, the model implies that there is a missing variable in the PPP equation, the ratio of nominal spendings, and that the ceteris paribus effect of higher domestic prices is a drop in the value of foreign currencies rather than a rise (as predicted by PPP). In models with non-homothetic, non-CRRA utility functions the exchange rate change depends not only on the standard ("average") inflation differential across countries (as in the PPP model) but also on the inflation differential computed on the basis of marginal consumption weights, growth in real spending, and the possibly time-varying degree of risk aversion in the two countries. Thus, standard regression or cointegration tests of PPP suffer from missing-variables biases and ignore variations in risk aversions across countries and over time.

We also present cointegration test of the equilibrium exchange rate model with constant relative risk aversion and homothetic preferences. The results of empirical testing appear to yield few definitive conclusions; in that sense they seem to accord with an observation of Froot and Rogoff(1994): "cointegration approaches have sometimes created as much confusion as clarity on the issue of PPP." One clear implication, however, is that a long-run equilibrium PPP relation between nominal exchange rates and the relevant price levels does emerge if money stocks are allowed to play a role in the short-run dynamics of the system, next to (and independently of) the price levels. Given that one lets money supplies play this role, the hypothesis of stationary combinations represented by equation (2.9) receives some support for values of risk aversion parameters which are both theoretically and empirically acceptable when tested for one country at the time. A related conclusion is that the structure of equilibrium relations revealed by-or extracted from-a given data set depend crucially upon the specification of the VAR model in 
levels, in particular which variables are included in and excluded from the system being estimated.

We see two challenges for future research in this area. First, more powerful tests are needed to sort out the roles of nominal spending and prices in the long-run relationship. Second, one needs to find an explanation for the empirical result that nominal money stocks seem to play an independent role in the short-term dynamics. In a model such as ours, only real spending matters. Possible approaches could be fluctuations in the velocity of money, or money-in-theutility-function effects. Both routes suggest that interest rates should be incorporated into the model; and interest rate changes are likely to be related to short-term fluctuations in money supplies. 


\section{Glossary to Notation}

Arranged alphabetically

\begin{tabular}{|c|c|}
\hline$c_{k j}(t)$ & consumption of good $\mathrm{j}$ in country $\mathrm{k}$ at time $\mathrm{t}$ \\
\hline $\mathcal{c}_{k}(t)$ & vector of consumption quantities $c_{k j}(t)$ of $\operatorname{good} j(=1, \ldots, N)$ in country $k$ \\
\hline$\Phi$ & $\begin{array}{l}\text { function indicating a positive monotone transformation, reflects degree of risk } \\
\text { aversion }\end{array}$ \\
\hline$\eta(t)$ & $=\frac{-M_{k} \partial^{2} V_{k} / \partial M_{k}^{2}}{\partial V_{k} / \partial M_{k}}$, degree of relative risk aversion (in real terms) \\
\hline j & subscript used to refer to a particular good \\
\hline $\mathbf{k}$ & subscript used to refer to a particular country ( $k=1$ is the home country) \\
\hline$\Lambda_{\mathbf{k}}(\mathrm{t})$ & $=\frac{\partial \mathrm{V}\left(\mathrm{M}_{\mathrm{k}}(\mathrm{t}), \mathrm{p}_{\mathrm{k}}(\mathrm{t})\right)}{\partial \mathrm{M}_{\mathrm{k}}(\mathrm{t})}$, the marginal indirect utility of nominal spending in country $\mathrm{k}$ \\
\hline $\mathbf{M}$ & number of countries \\
\hline $\mathbf{M}_{\mathrm{k}}(\mathrm{t})$ & amount of nominal spending in country $\mathbf{k}$ \\
\hline $\mathbf{N}$ & number of goods \\
\hline $\mathrm{n}_{\mathbf{j}}$ & number of shares of asset $\mathrm{j}$ held in investor's portfolio \\
\hline$\Pi_{k}$ & price level, computed on the basis of average consumption \\
\hline$\pi_{\mathrm{k}}$ & $\mathrm{d} \pi_{\mathrm{k}} / \pi_{\mathrm{k}}=$ inflation, computed on the basis of marginal consumption \\
\hline $\mathrm{p}_{\mathrm{kj}}(\mathrm{t})$ & the local currency price of good $\mathrm{j}$ in country $\mathrm{k}$ \\
\hline pk & $\log \Pi_{k}(t)$ \\
\hline$\theta_{\mathrm{k}}$ & relative weight assigned by the central planner to each country $\left(\theta_{1}=1\right)$ \\
\hline$\rho$ & subjective discount rate \\
\hline$S(t)$ & nominal exchange rate (nominal value of one unit of foreign currency) \\
\hline $\mathbf{u}_{\mathbf{k}}$ & function that is linear homogenous in consumption quantities \\
\hline $\mathrm{U}_{\mathrm{k}}$ & utility function of the representative investor in country $\mathrm{k}$ \\
\hline $\mathbf{U}$ & $\begin{array}{l}\text { the period-by-period utility of the central planner (derived from current } \\
\text { consumption aggregated over all } \mathrm{M} \text { countries) }\end{array}$ \\
\hline$V\left(M_{k}(t), p_{k}(t)\right)$ & the indirect utility of nominal spending in country $k$ \\
\hline $\mathrm{v}\left(\mathrm{M}_{\mathrm{k}}(\mathrm{t}), \mathrm{p}_{\mathrm{k}}(\mathrm{t})\right)$ & the indirect utility of nominal spending in the linear homogenous case \\
\hline $\mathrm{Z}(\mathrm{t})$ & the real exchange rate \\
\hline
\end{tabular}




\section{Figure 1}
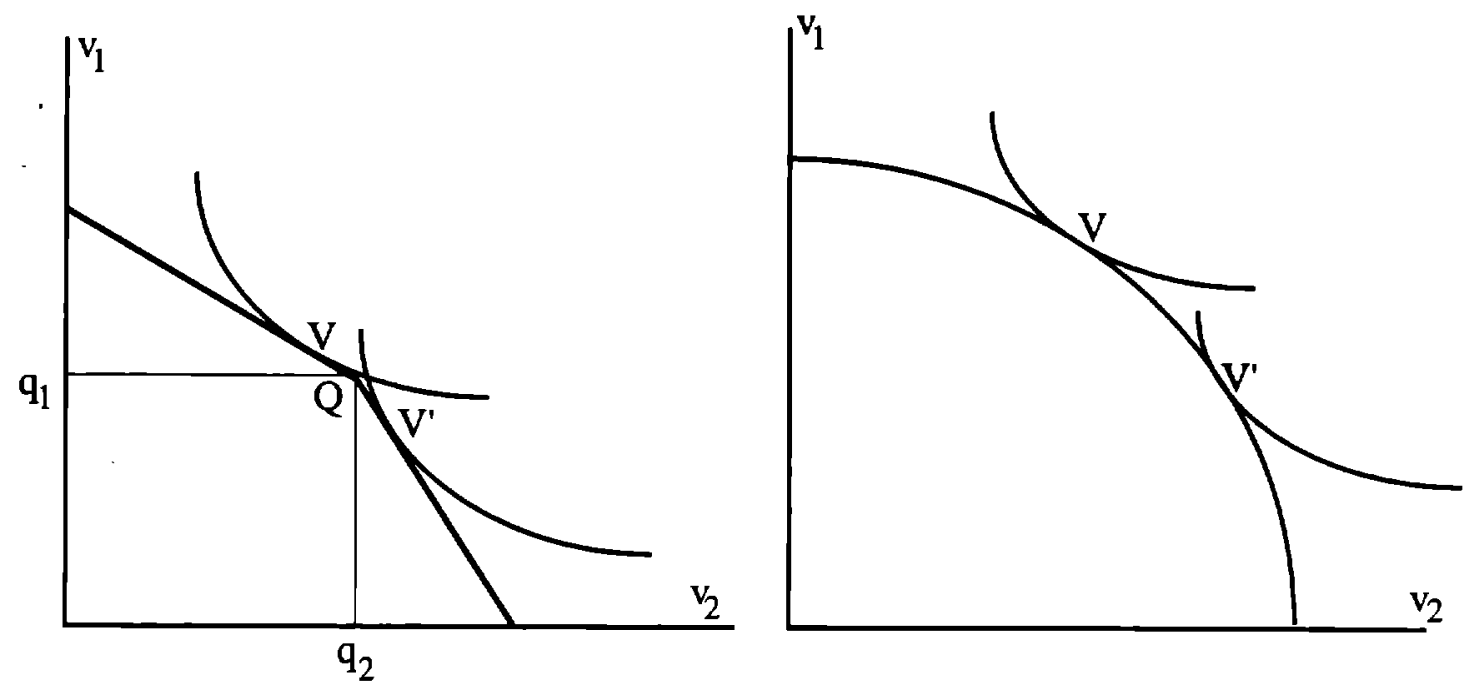

Key to Figure 1. The figure on the left assumes a one-good, two-country economy with endowments $Q=\left(q_{1}\right.$, q2). As there is but one good, $v_{k}$ equals $c_{k}$. There is a proportional shipment cost, $\tau$. Thus, if the consumption point $\mathrm{V}=\left(\mathrm{v}_{1}, \mathrm{v}_{2}\right)$ is above and to the left of $\mathrm{Q}$-that is, when country 1 is importing-the consumption opportunity set has a slope $-d v_{1} / d v_{2}=1 /(1+\tau)$. Likewise, if the consumption point $V=\left(v_{1}, v_{2}\right)$ is below and to the right of $\mathrm{Q}$ - that is, when country 1 is exporting-the consumption opportunity set has a slope $-\mathrm{dv}_{1} / \mathrm{dv}_{2}$ $=1+\tau$. If $\theta_{2}<(>) 1$, the central planner favors country 1 (2), and equilibria like $V\left(V^{\prime}\right)$ with a real exchange rate equal to $1 /(1+\tau)<1(1+\tau>1)$ become more likely. The figure on the right assumes two goods, no frictions, and different consumption preference functions $u_{k}\left(c_{k}, c_{k 2}\right)$. The international opportunity set for real spending $\left(\mathrm{v}_{2}, \mathrm{v}_{1}\right)$ is strictly convex. To show this it suffices to replace, in a Heckscher-Ohlin model, the (linear homogenous) production functions and the factor endowments, $\mathrm{K}$ and $\mathrm{L}$, by the (linear homogenous) preference functions $u_{k}(c)$ and the total endowments, $q_{j}=q_{1 j}+q_{2 j}$ respectively. Thus, the bound of the opportunity set is linear (strictly convex) if the consumption preferences are equal (different). The larger $\theta_{2}$, the more to the right the optimal consumption point, and the higher the MRS (the real exchange rate for country 2). 
Table 1: ADF Unit Root Test Results

\begin{tabular}{|c|c|c|c|c|c|}
\hline Series & ADF t-test & Series & ADF t-test & Series & ADF t-test \\
\hline $\begin{array}{l}s_{B E} \\
s_{S W} \\
s_{G E} \\
s_{U K} \\
s_{J P}\end{array}$ & $\begin{array}{l}-2.0047 \\
-2.7169 \\
-2.2176 \\
-2.4062 \\
-2.9324\end{array}$ & $\begin{array}{l}\text { p } \\
\text { PSE } \\
\text { PGE } \\
\text { PUK } \\
\text { PJP } \\
\text { PUS }\end{array}$ & $\begin{array}{l}-2.6100 \\
-3.2411 \\
-1.9687 \\
-2.9429 \\
-2.9831 \\
-1.7852\end{array}$ & $\begin{array}{l}\mathrm{m}_{\mathrm{BE}} \\
\mathrm{m}_{\mathrm{SW}} \\
\mathrm{m}_{\mathrm{GE}} \\
\mathrm{m}_{\mathrm{UK}} \\
\mathrm{m}_{\mathrm{JP}} \\
\mathrm{m}_{\mathrm{US}}\end{array}$ & $\begin{array}{l}-3.0292 \\
-3.4662 \\
-2.2772 \\
-2.0361 \\
-2.7261 \\
-3.6815\end{array}$ \\
\hline
\end{tabular}

Key to Table 1. The table shows the t-statistic for the ADF Unit Root Test with a time trend for the seventeen variables (in log form) listed. The 95\% Critical Value for 250 observations is -3.43.[Hamilton(1994), Table B.6, p. 763, Case 4].

Table 2: $L_{\max }$ and Trace Statistics for Nominal Exchange Rates and Prices ( $\mathrm{p}=11$ series)

\begin{tabular}{lrrr|llll} 
Eigenv. & L-max & Trace & $\mathrm{H}_{0}: \mathrm{r}$ & Eigenv. & L-max & Trace & $\mathrm{H}_{0}: \mathrm{r}$ \\
\hline 0.4289 & 129.41 & 573.96 & 0 & 0.1402 & 34.90 & 93.74 & 6 \\
0.3496 & 99.37 & 444.55 & 1 & 0.1084 & 26.50 & 58.84 & 7 \\
0.3241 & 90.50 & 345.19 & 2 & 0.0854 & 20.63 & 32.34 & 8 \\
0.2622 & 70.25 & 254.69 & 3 & 0.0467 & 11.06 & 11.71 & 9 \\
0.1886 & 48.28 & 184.44 & 4 & 0.0028 & 0.66 & 0.66 & 10 \\
0.1678 & 42.42 & 136.16 & 5 & & & & \\
\hline
\end{tabular}

Key to Table 2. The table shows the Eigenvalues, $\mathrm{L}_{\max }$, and trace tests within the 11-variable system (exchange rates and relative prices). The $90 \%$ critical values, from Osterwald-Lenum(1992), Table 1, p.468, are:

$$
\begin{array}{rrrr}
\mathrm{p}-\mathrm{r} & 1 & 2 & 3 \\
\mathrm{~L}_{\max } & 18.60 & 12.07 & 2.69 \\
\text { Trace } & 26.79 & 13.33 & 2.69
\end{array}
$$

At this significance level, there are nine cointegration relations in this data set. 
Table 3 : Likelihood Ratio Tests for the PPP(1) Hypothesis ( $\mathrm{p}=11$ series) Currency $\chi^{2}(\mathrm{df}) \mathrm{p}$-value

$\begin{array}{llll}\text { Belgian Franc } & 6.44 & (2) & 0.04 \\ \text { Swiss Franc } & 9.59 & (2) & 0.01 \\ \text { Deutsche Mark } & 9.17 & (2) & 0.01 \\ \text { British Pound } & 9.16 & (2) & 0.01 \\ \text { Japanese Yen } & 9.79 & (2) & 0.01\end{array}$

All Currencies simultaneously $27.96 \quad(10) \quad 0.00$

Key to Table 3. The table shows the $\chi^{2}$-tests, degrees of freedom, and probability values for the PPP hypothesis in the 11-variable data set without money stocks. There are nine cointegration relations in this data set (Table 2). In the country-by-country tests, the PPP-vector is imposed one country at the time; that is, in each such test the other eight cointegration vectors are left unrestricted. In the test labeled "all countries simultaneously", five PPP-vectors are imposed simultaneously and four are left unrestricted.

Table 4: $L_{\max }$ and Trace Statistics for Nominal Exchange Rates, Prices, and Money Stocks ( $p=17$ series)

\begin{tabular}{cccc|cccc} 
Eigenv. & L-max & Trace & $\mathrm{H}_{0}: \mathrm{r}$ & Eigenv. & L-max & Trace & $\mathrm{H}_{0}: \mathrm{r}$ \\
\hline 0.6956 & 274.74 & 1879.65 & 0 & 0.2881 & 78.51 & 336.24 & 9 \\
0.6388 & 235.26 & 1604.92 & 1 & 0.2678 & 72.00 & 257.73 & 10 \\
0.5905 & 206.26 & 1369.65 & 2 & 0.2041 & 52.73 & 185.74 & 11 \\
0.5233 & 171.14 & 1163.39 & 3 & 0.1738 & 44.09 & 133.01 & 12 \\
0.4941 & 157.39 & 992.25 & 4 & 0.1527 & 38.29 & 88.92 & 13 \\
0.4755 & 149.07 & 834.87 & 5 & 0.1291 & 31.93 & 50.63 & 14 \\
0.4234 & 127.18 & 685.79 & 6 & 0.0774 & 18.61 & 18.70 & 15 \\
0.3901 & 114.23 & 558.62 & 7 & 0.0004 & 0.09 & 0.09 & 16
\end{tabular}

Key to Table 4. The table shows the Eigenvalues, $\mathrm{L}_{\max }$, and trace tests within the 17-variable system (exchange rates and relative prices). See Table 2 for the $90 \%$ critical values. At this significance level, there are sixteen cointegration relations in this data set. 
Table 5 : Likelihood Ratio Tests for the PPP(2) and CRRA(1) Hypotheses $(p=17$ series)

\begin{tabular}{l|ccc|ccc} 
& \multicolumn{3}{|c|}{$\eta_{\mathrm{US}}=1.25 ; \eta_{\mathrm{k}}=1.50$} & \multicolumn{3}{|c}{$\eta_{\text {US }}=0.60 ; \eta_{\mathbf{k}}=0.40$} \\
Currency & $\chi^{2}$ & $(\mathrm{df})$ & $\mathrm{p}$-value & $\chi^{2}$ & $(\mathrm{df})$ & p-value \\
\hline Belgian Franc & 1.33 & $(1)$ & 0.25 & 0.11 & $(1)$ & 0.74 \\
Swiss Franc & 17.73 & $(1)$ & 0.00 & 2.70 & $(1)$ & 0.10 \\
Deutschemark & 0.32 & $(1)$ & 0.57 & 0.12 & $(1)$ & 0.73 \\
British Pound & 1.13 & $(1)$ & 0.29 & 0.75 & $(1)$ & 0.39 \\
Japanese Yen & 0.01 & $(1)$ & 0.92 & 0.14 & $(1)$ & 0.71 \\
All Currencies & 36.07 & $(5)$ & 0.00 & 32.21 & $(5)$ & 0.00 \\
simultaneously & & & & &
\end{tabular}

\begin{tabular}{l|rrr|ccc} 
& \multicolumn{3}{|c|}{$\eta_{\mathrm{US}}=0.05 ; \eta_{\mathbf{k}}=0.05$} & \multicolumn{3}{|c}{$\eta_{\text {US }}=0.00 ; \eta_{\mathbf{k}}=0.00$} \\
Currency & $\chi^{2}$ & $(\mathrm{df})$ & p-value & $\chi^{2}$ & (df) & p-value \\
\hline Belgian Franc & 0.26 & $(1)$ & 0.61 & 0.33 & $(1)$ & 0.57 \\
Swiss Franc & 0.03 & $(1)$ & 0.87 & 0.00 & $(1$ & 0.95 \\
Deutschemark & 0.15 & $(1)$ & 0.70 & 0.21 & $(1)$ & 0.65 \\
British Pound & 0.00 & $(1)$ & 0.96 & 0.04 & $(1)$ & 0.84 \\
Japanese Yen & 0.85 & $(1)$ & 0.36 & 0.94 & $(1)$ & 0.33 \\
All Currencies & 2.63 & $(5)$ & 0.03 & 12.87 & $(5)$ & 0.02 \\
simultaneously & & & & &
\end{tabular}

Key to Table 5. The table shows the $\chi^{2}$-tests, degrees of freedom, and probability values for the PPP(2) and CRRA(1) hypotheses in the 17-variable data set (including money stocks). There are sixteen cointegration relations in this data set (Table 4). In the country-by-country tests, the PPP-or CRRA-vector is imposed one country at the time; that is, in each such test the other fifteen cointegration vectors are left unrestricted. In the test labeled "all countries simultaneously", five vectors are imposed simultaneously and eleven are left unrestricted.

Table 6: $L_{\max }$ and Trace Statistics for Nominal Exchange Rates and Prices ( $p=11$ series)

\begin{tabular}{lrrr|rrrr} 
Eigenv. & L-max & Trace & $\mathrm{H}_{0}: \mathbf{r}$ & Eigenv. & L-max & Trace & $\mathrm{H}_{0}: \mathbf{r}$ \\
\hline 00.4131 & 123.09 & 492.64 & 0 & 0.1268 & 31.31 & 77.98 & 6 \\
00.2729 & 73.62 & 369.55 & 1 & 0.0915 & 22.16 & 46.67 & 7 \\
00.2586 & 69.12 & 295.93 & 2 & 0.0701 & 16.79 & 24.51 & 8 \\
00.2158 & 56.14 & 226.81 & 3 & 0.0327 & 7.69 & 7.72 & 9 \\
00.2016 & 52.02 & 170.67 & 4 & 0.0001 & 0.03 & 0.03 & 10 \\
00.1614 & 40.67 & 118.65 & 5 & & & &
\end{tabular}

Key to Table 6. The table shows the Eigenvalues, $\mathrm{L}_{\max }$, and trace tests within the 11-variable system (real exchange rates and real money stocks). See Table 2 for the $90 \%$ critical values. At this significance level, the Lmax (trace) statistic suggests the existence of seven (eight) cointegration relations in this data set. 
Table 7 : Likelihood Ratio Tests for Stationarity of the Real Exchange Rate (17 series)

\begin{tabular}{l|lll|lll} 
& \multicolumn{3}{|c|}{$\eta_{\mathrm{US}}=3.00 ; \eta_{\mathrm{k}}=2.00$} & \multicolumn{3}{c}{$\eta_{\mathrm{US}}=1.25 ; \eta_{\mathrm{k}}=1.50$} \\
Currency & $\chi^{2}$ & $(\mathrm{df})$ & $\mathrm{p}$-value & $\chi^{2}$ & $(\mathrm{df})$ & p-value \\
\hline Belgian Franc & 17.73 & $(4)$ & 0.07 & 12.98 & $(4)$ & 0.01 \\
Swiss Franc & 9.79 & $(4)$ & 0.01 & 12.50 & $(4)$ & 0.01 \\
Deutschemark & 25.50 & $(4)$ & 0.00 & 21.36 & $(4)$ & 0.00 \\
British Pound & 13.22 & $(4)$ & 0.01 & 12.68 & $(4)$ & 0.01 \\
Japanese Yen & 20.37 & $(4)$ & 0.02 & 15.61 & $(4)$ & 0.00
\end{tabular}

\begin{tabular}{l|ccc|ccc} 
& \multicolumn{3}{|c|}{$\eta_{\text {US }}=0.05 ; \eta_{\mathbf{k}}=0.05$} & \multicolumn{3}{c}{$\eta_{\text {US }}, \eta_{\mathbf{k}}$ left unspecified } \\
Currency & $\chi^{2}$ & $(\mathrm{df})$ & $\mathrm{p}$-value & $\chi^{2}$ & (df) & p-value \\
\hline & & & & & & \\
Belgian Franc & 23.35 & $(4)$ & 0.00 & 5.32 & $(2)$ & 0.07 \\
Swiss Franc & 24.02 & $(4)$ & 0.00 & 9.89 & $(2)$ & 0.01 \\
Deutschemark & 25.19 & $(4)$ & 0.00 & 12.46 & $(2)$ & 0.00 \\
British Pound & 23.64 & $(4)$ & 0.00 & 8.73 & $(2)$ & 0.01 \\
Japanese Yen & 22.03 & $(4)$ & 0.00 & 7.69 & $(2)$ & 0.02
\end{tabular}

Key to Table 7. The table shows the $\chi^{2}$-tests, degrees of freedom, and probability values for the CRRA(3) hypothesis in the 11-variable data set (real exchange rates, real money stocks). We assume there are seven cointegration relations in the data (Table 6). In the country-by-country tests, the CRRA-vector is imposed one country at the time; that is, in each such test the other six cointegration vectors are left unrestricted. 


\section{References}

Apte, P., M. Kane, and P. Sercu (1994): Relative PPP in the Medium Run, Journal of International Money and Finance, 13, 602-622.

Backus, D., G. Smith (1993): Consumption and Real Exchange Rates in Dynamic Economies with Non-traded Goods, Journal of International Economics 35, 297-316.

Balassa, B. (1964): The Purchasing Power Parity Doctrine: a Reappraisal, Journal of Political Economy, 72, 584-96

Bekaert, G. (1994): Exchange Rate Volatility and Deviations for Unbiasedness in a Cash-inAdvance model, Journal of International Economics, 36, 29-52

Breeden, D. (1979): An Intertemporal Asset Pricing Model with Stochastic Consumption and Investment Opportunities, Journal of Financial Economics, 7, 265-296.

Dickey, D.A. and R.J. Rossana (1994): "Cointegrated Time Series: A Guide to Estimation and Hypothesis Testing" Oxford Bulletin of Economics and Statistics, 56, 325-353.

Domowitz, I., and C. Hakkio (1985): Conditional Variance and the Risk Premium in the Foreign Exchange Market, Joumal of International Economics, 19, 47-66.

Dumas, B. (1992): Dynamic Equilibrium and the Real Exchange Rate in a Spatially Separated World, The Review of Financial Studies, 5, 153-180.

Engel, C. M. (1992a): On the Foreign Exchange Risk Premium in a general Equilibrium Model, Joumal of International Economics, 32, 305-319.

Engel, C. M. (1992b): The Risk Premium and the Liquidity Premium in Foreign Exchange Markets, International Economic Review, 32, 305-319.

Engle, R.F. and C.W.J. Granger (1987): Cointegration and Error Correction: Representation, Estimation and Testing, Econometrica, 55, 251-276.

Froot, K.A. and K. Rogoff (1994): Perspectives on PPP and Long-Run Real Exchange Rates, NBER Working Paper Series, No.4952.

Granger, C.W.J. (1981): Some Properties of Time Series Data and their Use in Econometric Model Specification, Journal of Econometrics, 16, 121-130.

Hamilton, J.D. (1994):Time Series Analysis, Princeton University Press, Princeton, N.J.

Hansen, H. and K. Juselius (1995): CATS in RATS Cointegration Analysis of Time Series, ESTIMA, Evanston Ill.

Hodrick, R.J., and S. Srivastava (1986): The Covariation of Risk Premiums and Expected Future Exchange Rates, Journal of International Money and Finance, 5 (Supplement), S5-21 
Johansen, S. (1988): Statistical Analysis of Cointegration Vectors, Joumal of Economic Dynamics and Control, 12, 231-254.

Johansen, S. (1991): Estimation and Hypothesis Testing of Cointegration Vectors in Gaussian Vector Autoregressive Models, Econometrica, 59, 1551-1580.

Johansen, S. and K. Juselius (1990): Maximum Likelihood Estimation and Inference on Cointegration-with Applications to the Demand for Money, Oxford Bulletin of Economics and Statistics, 52, 169-210.

Johansen, S. and K. Juselius (1992): Testing Structural Hypotheses in a Multivariate Cointegration Analysis of the PPP and the UIP for UK, Joumal of Econometrics 53, 211-244.

Lewis, K. (1995): Puzzles in International Financial Markets, Working paper, Wharton School, University of Pennsylvania, forthcoming in Grossman, G., and K. Rogoff, eds., Handbook of International Economics, North Holland, Amsterdam.

Lucas, R. (1982): Interest Rates and Currency Prices in a Two-Country World, Journal of Monetary Economics 10, 335-359.

Mark, N. (1985): On Time-Varying Risk Premia in the Foreign Exchange Market, Journal of Monetary Economics, 16, 3-18

Nessén, M. (1994): Common Trends in Prices and Exchange Rates-Tests of Long-Run Purchasing Power Parity, Essay I in Essays on Exchange Rates and International Finance, Unpublished Doctoral Dissertation, Department of Finance, Stockholm School of Economics.

Osterwald-Lenum, M. (1992): A Note with Quantiles of the Asymptotic Distribution of the Maximum Likelihood Cointegration Rank Test Statistics, Oxford Bulletin of Economics and Statistics, 54, 461-471.

Phillips, P.C.B. (1990): Optimal Inference in Cointegrated Systems, Econometrica, 59, 283-306.

Samuelson, P. (1964): Theoretical Notes on Trade Problems, Review of Economics and Statistics, 46, 145-54/

Samuelson, P., and S. Swamy (1974): Invariant Index Numbers and Canonical Duality: Survey and Synthesis, American Economic Review , 64, 566-593.

Sercu, P., R. Uppal and C. Van Hulle (1995): “The Exchange Rate in the Presence of Transactions Costs: Implications for Tests of Purchasing Power Parity" Joumal of Finance, September 50, 1309-1319.

Singleton, K. (1990): Specification and Estimation of Intertemporal Asset Pricing Models, in B. Friedman and F. Hahn, eds: Handbook of Monetary Economics (North Holland, Amsterdam).

Stock, J.H. and M.W. Watson (1988): Testing for Common Trends, Journal of the American Statistical Association, 83, 1097-1107. 
Stockman, A. (1980): A Theory of Exchange Rate Determination, Journal of Political Economy, 88, 673-698.

Stockman, A. and H. Dellas (1989): International Portfolio Nondiversification and Exchange Rate Variability, Journal of International Economics, 26, 261-290.

Stulz, R. (1987): An Equilibrium Model of Exchange Rate Determination and Asset Pricing with Nontraded Goods and Imperfect Information, Journal of Political Economy, 95, 10241040.

Svensson, L. E. O. (1985a): Currency prices, terms of Trade, and Interest Rates: A General Equilibrium Asset Pricing Cash-in-Advance Approach, Journal of International Economics, 18, 17-42.

Svensson, L. E. O. (1985b): Money and Asset Prices in a Cash-in-Advance Economy, Journal of Political Economy, 93, 919-944. 